\title{
ARQUEOLOGÍA Y EDUCACIÓN FORMAL EN LA COSTA DE TALTAL-PAPOSO: REFLEXIONES SOBRE "ARQUEOLOGÍA PÚBLICA"
}

\author{
ARCHAEOLOGY AND FORMAL EDUCATION IN THE COAST OF TALTAL- \\ PAPOSO: CRITICAL THROUGHTS ON "PUBLIC ARCHAEOLOGY"
}

\author{
Diego Salazar ${ }^{1}$, Josefina Urrea-Navarrete ${ }^{2}$, Manuel Escobar ${ }^{3}$,Pedro Andrade ${ }^{2}$, Mónica Muñoz, \\ Cecilia Maldonado ${ }^{4}$, Romina Torres ${ }^{3}$ y Karina Vargas $^{3}$
}

\begin{abstract}
Con el objeto de contribuir a la formación de sujetos históricos en el marco del actual sistema educativo formal de la Comuna de Taltal, hemos desarrollado un proyecto que vincula los conocimientos académicos que hemos generado sobre el territorio y su (pre)historia en el marco de tres proyectos Fondecyt sucesivos, con saberes locales no académicos y con estrategias pedagógicas y didáctica de enseñanza-aprendizaje que responden a los objetivos de los planes curriculares del Ministerio de Educación, contextualizándolos a la realidad local. El presente trabajo sintetiza los alcances del proyecto y discute las posibilidades de profundizar los vínculos entre arqueología y educación formal en el marco de una arqueología pública crítica.

Palabras claves: educación formal, arqueología pública, Comuna de Taltal.
\end{abstract}

In this paper, we summarize the scope of a project that we have developed in order to make a contribution to the training of local critical agents within the frame of the current educational system of Taltal, in northern Chile. The goal of the project is to connect the academic knowledge on the territory and its (pre)history, which we have produced through three successive research projects, with local non-academic knowledge, educational strategies, and teaching-learning methodologies, which meet the objectives of Ministry of Education's official curricular programs, but from a local context. We also reflect on the possibilities of strengthening the ties between archaeology and formal education within the frame of a critical public archaeology.

Key words: Formal education, public archaeology, Taltal.

El modelo de ciencia asentado en las últimas décadas en Europa, Estados Unidos y buena parte de los países Latinoamericanos, incluido Chile, privilegia la productividad académica y la "innovación", potenciando la hiperespecialización, individualismo y competitividad de la práctica científica, fragmentando el conocimiento y desvinculándolo de las comunidades locales (Bianco et al. 2014; Vasen 2011; Vessuri 2013; Vessuri et al. 2014). En el caso de Chile, lo anterior se evidencia en que las instituciones que financian las investigaciones (léase Conicyt y, en particular, su programa Fondecyt), no consideran relevante o un requisito excluyente para calificar un proyecto y asignarle fondos públicos, su relevancia o sentido social en el presente (Salazar et al. 2017).

A nivel mundial, y desde distintas vertientes, la arqueología ha reaccionado ante esta situación, tratando de fomentar la difusión y aporte social de sus conocimientos académicos, retomando ideas pioneras de las primeras arqueologías socialmente comprometidas, en especial las de corte marxista, como es el caso de la Arqueología Social Latinoamericana (cf. Delfino y Rodríguez 1991; Lorenzo et al. 1976; Vargas y Sanoja 1990), la Arqueología Crítica norteamericana (Leone et al. 1987), y algunos proyectos nacionalistas y emancipadores africanos (Holl 1995). Es en este contexto que surge y se desarrolla la denominada "arqueología pública", la cual, junto con sus variantes indígena, comunitaria, dialógica, poscolonial, colaborativa y multivocal, entre otras, refleja la gama amplia y diversa de aproximaciones que actualmente se discuten respecto a la responsabilidad social de la disciplina y sus vinculaciones con la sociedad mayor.

\footnotetext{
${ }^{1}$ Departamento de Antropología, Universidad de Chile, Santiago, Chile. dsalazar@uchile.cl

2 Carrera de Antropología, Facultad de Ciencias Sociales, Universidad de Concepción, Concepción, Chile. jourrea@udec.cl; pandradem@udec.cl 3 Investigador Independiente. mem1074@gmail.com; muchoskiwis.design@gmail.com; k.v.neira@gmail.com

${ }^{4}$ Departamento de Curriculum e Instrucción, Facultad de Educación, Universidad de Concepción, Concepción, Chile. monmunoz@udec.cl; cemaldon@udec.cl
} 
Si bien es cierto que en Chile el campo disciplinar de la "arqueología pública" no ha alcanzado el grado de especialización de otras regiones del mundo con mayor cantidad de arqueólogos, hace ya más de 10 años era evidente una tendencia creciente de la disciplina hacia los temas de "difusión" y "educación patrimonial" (Carrasco 2006), tendencia que se ha incrementado y consolidado en los últimos tiempos, a juzgar por la gran diversidad de iniciativas que se han llevado a cabo en la actualidad, de las cuales lamentablemente solo una parte de éstas termina siendo publicada (véase Carrión et al. 2015 para una síntesis crítica).

A pesar de los avances alcanzados, uno de los campos menos explorados en esta tendencia en Chile y el mundo hacia el rol social del conocimiento arqueológico, es la relación entre arqueología y educación formal. Las políticas públicas de los Estados Nacionales han delegado en la educación formal la transmisión de conocimientos y preparación para la vida social de las nuevas generaciones (Celorio y Goño 1989), promoviendo un curriculum que intenta abordar temáticas de pertinencia cultural. Sin embargo, no se han incluido estrategias que permitan una integración real y actualizada de conocimientos sobre la (pre) historia local, existiendo una virtual ausencia de aportes sistemáticos desde la arqueología en este campo, lo que por lo tanto implica un escaso aporte de la disciplina a la reproducción social.

Generar un impacto sobre las políticas públicas educativas de un Estado es, por supuesto, una tarea muy compleja, lo cual explica en parte la falta de desarrollo de esta temática dentro de la arqueología pública mundial. No obstante, presenta también un enorme potencial para la disciplina en términos de generar un aporte relevante en procesos de transformación social en el mediano y largo plazo (Aguilera 2015), sobre todo en la medida de que se aproveche el "giro multicultural" de las políticas públicas de numerosos Estados Nacionales, y se lo dote de una perspectiva crítica (Cosalan y Rebolledo 2017).

En efecto, el "giro multicultural" ha abierto espacios para que la arqueología profundice sus vínculos con la educación formal y participe de iniciativas de cambio social al otorgarle importancia a los procesos históricos e identidades locales. No obstante, ni la arqueología ni el sistema educativo formal han logrado proveer de los mecanismos suficientes o adecuados para fortalecer el conocimiento y valoración de dichas realidades locales (Gómez 2004; Melo 2018; Vergara 2008) y, por lo tanto, en la práctica continúan reproduciendo los discursos dominantes por medio de los textos escolares y material entregado a los y las docentes (Ajagán y Turra 2009). Debido a que el modelo educativo actual carece de estrategias pedagógicas adecuadas a la realidad local, tanto en términos de contenidos pertinentes como de recursos didácticos, en la práctica en la gran mayoría de las comunas de Chile la comunidad educada en el sistema formal es socializada a partir de contenidos provenientes de otros contextos histórico-sociales. Uno de los ejemplos más claros y dramáticos es la enseñanza de la historia (Vergara 2008), hasta hace pocos años denominada "historia universal" e "Historia de Chile", pero que en realidad es principalmente la historia de Europa Occidental y de las élites americanas y chilenas post-conquista, respectivamente. La situación descrita no es, por supuesto, exclusiva de Chile. A nivel mundial se ha reconocido cómo el pasado (y el presente) de las comunidades locales es frecuentemente "excluido" del curriculum oficial, reproduciéndose a partir de esta exclusión condiciones coloniales, de marginalidad, desarraigo y/o desigualdad social (Stone y Mckenzie 1990; Stone y Molyneaux 1994; Vargas y Sanoja 1990).

Para contribuir a revertir esta situación desde la arqueología pública, se requiere que la disciplina dialogue con otros actores, en especial del mundo de la educación, para convertir los saberes académicos y también los saberes locales no-académicos en estrategias pedagógicas y didácticas que formen parte integral de procesos de socialización crítica dentro de las comunidades locales (Sanoja y Vargas 1993).

En el presente trabajo intentamos avanzar en esa dirección, dando cuenta de una experiencia de diálogo entre la investigación arqueológica y la educación formal y proponiendo algunas reflexiones acerca de una arqueología pública con vocación crítica. La experiencia en cuestión se ha desarrollado en la Comuna de Taltal, en el norte de Chile, y se ha orientado al diseño e implementación de propuestas pedagógicas que promuevan el desarrollo del pensamiento crítico y situado, a partir de la incorporación de conocimientos sobre el territorio, la (pre)historia, las actividades tradicionales y el patrimonio local de la Comuna de Taltal, integrándose dentro de los programas educativos que establece el Ministerio de Educación y los establecimientos educacionales locales para los niveles de enseñanza prescolar y escolar.

\section{Arqueología Pública y Educación}

Durante las últimas dos o tres décadas se han multiplicado a nivel mundial las iniciativas que buscan vincular el conocimiento o la práctica arqueológica con la sociedad o el "público" fuera de la academia. El concepto de "arqueología pública" se ha hecho cada vez más popular en Europa Occidental, Estados Unidos y, en menor medida, América Latina, para dar cuenta de estas iniciativas, agrupando una diversidad amplia de experiencias, enfoques y propuestas (p.ej., Almansa 2013; Merriman 2004a; Moshenska 2017a; Okamura y Matsuda 2011; Salerno 2013; Vilches et al. 2015; entre muchos otros), llegando a conformar hoy verdaderos campos de 
ejercicio profesional e incluso verdaderas subdisciplinas dentro de la arqueología (Merriman 2002).

Chile no ha sido la excepción a esta tendencia. Si bien Carrión et al. (2015:101) afirman recientemente que "en Chile no existe un número significativo de trabajos escritos referidos a la difusión patrimonial", en nuestra opinión el número de iniciativas no es tan precario como parecen sugerir dichos autores (véase p.ej., Adán et al. 2001; Aguilera 2007, 2015; Aguilera et al. 2006; Aguilera y Prado 2010; Artigas y Salatino 2009; Ayala 2014; Ayala et al. 2003; Bravo 2015; Carrasco et al. 2003; Córdova et al. 2002; Córdova et al. 2004; Cosalán y Rebolledo 2017; Donoso et al. 2010; Godoy y Adán 2003; Godoy et al. 2003; Gómez 2004; González et al. 2010; Jofré 2012; Kalazich 2013, Ladrón de Guevara et al. 2003; Opazo 2016; Pascual 2010; Romero 2003; Romero et al. 2004 y 2015; Salatino y Artigas 2011; Salatino y Troncoso 2014; Salazar 2010; Seguel 1997; Uribe y Adán 2003; Uribe et al. 2017; Vergara 2008; Vilches et al. 2015). La importancia creciente de la "arqueología pública" en Chile se acrecienta si consideramos los numerosos proyectos financiados por fondos del ex Ministerio de la Cultura y las Artes y/o los Gobiernos Regionales (p.ej., Fondart, FNDR, etc.) que se han adjudicado arqueólogos y arqueólogas en la última década, así como las muchas iniciativas que no han sido publicadas académicamente, ni dadas a conocer en forma masiva.

Dentro del concepto de "arqueología pública" en el cual podemos subsumir estas iniciativas coexisten diversas formas de entender la relación entre la disciplina y su rol en la sociedad, muchas de ellas sin necesaria vinculación o coherencia entre sí (Vilches et al. 2005), aunque por lo general alineadas con la lógica multicultural y neoliberal imperante (Ayala 2014; Gnecco 2008; González-Ruibal et al. 2018; Matsuda 2016). En un esfuerzo de síntesis, aunque desde una perspectiva esencialmente anglosajona, Moshenska (2017b) identifica recientemente siete tipos principales de "arqueología pública". Para efectos de este artículo, nos interesa en especial resaltar que la "educación arqueológica" es solo una de las diversas aproximaciones posibles dentro de la arqueología pública, incluyendo aproximaciones vinculadas con la educación informal, formal y noformal, siendo la educación formal la menos explorada de entre las anteriores. En efecto, según Corbishley y Stone (1994:384) las discusiones acerca de la relación entre educación formal y arqueología se han limitado a "brief articles reporting successful classroom-based projects (...) as well as the almost passing reference to school education in a number of professional inaugural lectures (...) Even the occasional conferences organized specifically to discuss aspects of archaeology and education have been essentially descriptive". En uno de los trabajos más recientes sobre el tema, Henson
(2017:45) confirma lo anterior al plantear que "only a few writers have explored archaeology in education", mientras que el estudio de Cole (2014), uno de los más completos en términos de la compleja y multidimensional relación entre arqueología y educación formal, va aún más lejos al señalar que "as the general understanding of archaeological education is poor, so too is the understanding of its theoretical underpinnings" (Cole 2014:15). En Chile la situación es similar, ya que hace ya 25 años se constataba "el débil nexo que existe entre el avance de la ciencia arqueológica y la educación en el país" (Valdés et al. 1994:19), situación que no parece haber cambiado significativamente, a pesar de la creciente importancia de la arqueología pública a la que hemos hecho alusión.

Las escasas experiencias publicadas de "arqueología y educación formal" son clasificadas por Cole (2014) en cinco grandes tipos de aproximaciones prácticas, con un carácter principalmente descriptivo y metodológico ("práctico", sensu Ayala 2017), sin evidenciar explícitamente el o los objetivos sociales que persiguen. No obstante, algunas aproximaciones, especialmente en América Latina, destacan por un acercamiento más crítico al tema, centrándose en los objetivos sociales del involucramiento de la arqueología (o la historia) en la educación formal, o en los sesgos y efectos políticos de los curriculums vigentes, más que en las estrategias metodológicas mismas o en garantizar aprendizajes o valoraciones funcionales a la reproducción de la propia disciplina arqueológica (véase, p.ej., Cosalan y Rebolledo 2017; Figueroa y Silva 2006; García 2007; Gómez y Ocaranza 2012; Gómez et al. 2015; Montenegro 2012; Podgorny 2000; Vergara 2008; entre otros).

\section{Breve Caracterización Sociocultural de la Comuna de Taltal}

La Comuna de Taltal pertenece administrativamente a la Región de Antofagasta y abarca una superficie de $20.405,1 \mathrm{~km}^{2}$, la cual corresponde mayoritariamente a territorios rurales despoblados (Figura 1). La capital de la comuna y único centro urbano es la ciudad de Taltal, además existen dos poblados en las localidades de Caleta Cifuncho, al sur de Taltal, y Paposo ubicada al norte (PLADECO TALTAL 2016-2022). Taltal tiene una población de 13.317 habitantes, de los cuales 5.836 son mujeres y 7.481 hombres (CENSO 2017).

Las principales actividades productivas son la minería, la pesca, la recolección de orilla, y el comercio, actividades asociadas a modos de vida tradicionales que tienen una larga historia de continuidades y transformaciones en la zona.

Taltal es también históricamente una sociedad que ha acogido y se ha compuesto de población inmigrante, 


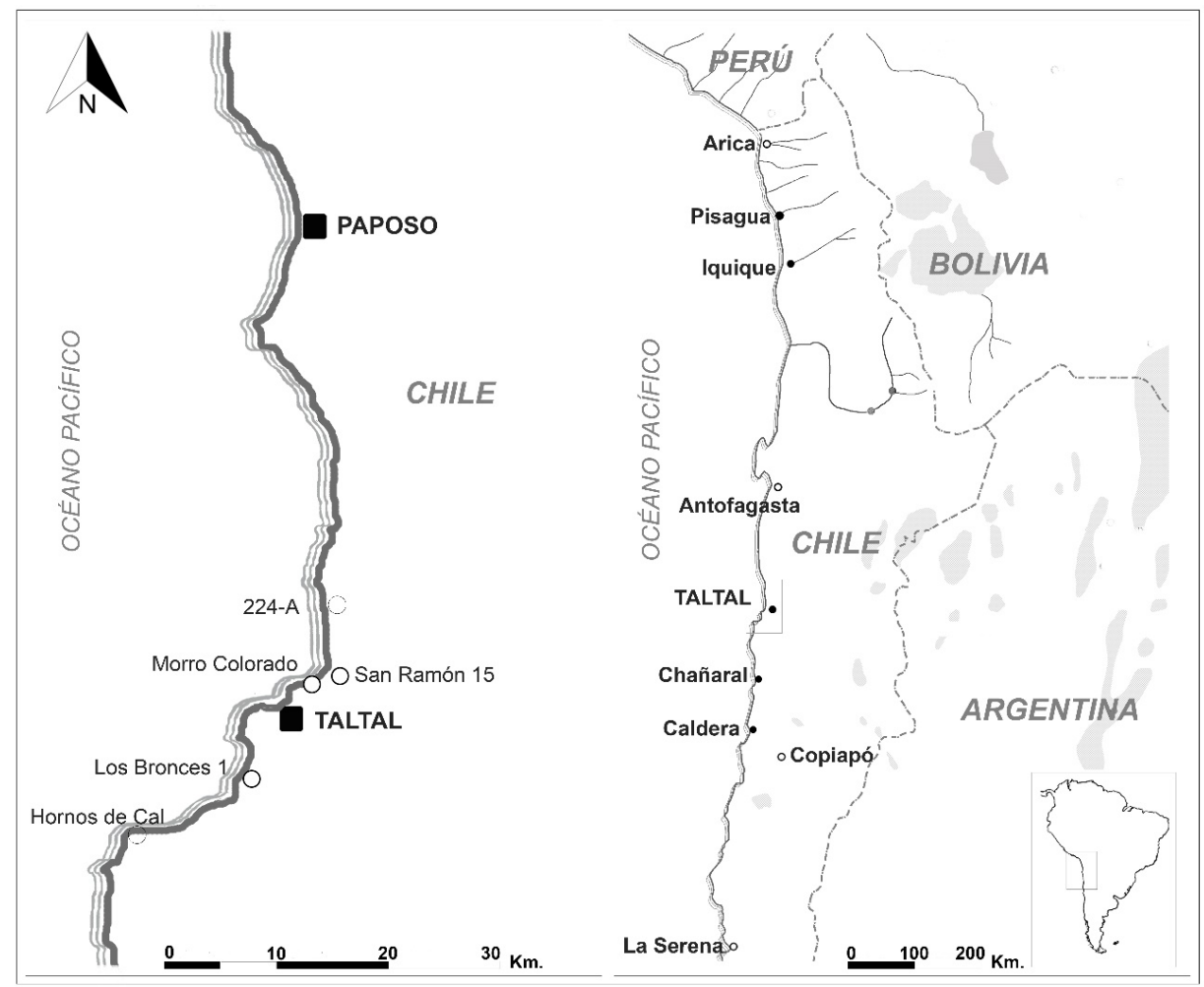

Figura 1. La ciudad de Taltal en el contexto geográfico regional. Se muestran los sitios arqueológicos que han sido visitados con actores locales en el marco del presente proyecto.

Taltal city in regional context. The location of archaeological sites visited with local actors during the project is shown.

situación que en años recientes ha cobrado una singular importancia gracias a la presencia de extranjeros latinoamericanos, que vienen de países vecinos como Perú o Bolivia, o más lejanos como Colombia o Venezuela. De igual manera, y paralelo a este complejo proceso de integración de las nuevas familias de inmigrantes, en la actualidad se vive un proceso de creciente reetnificación, mediante el cual comunidades costeras y autoridades municipales aspiran al reconocimiento constitucional de la antigua etnia "changa" en Chile, y a la conformación de comunidades indígenas changas a nivel local, con el objeto de defender y gestionar autónomamente el territorio y sus recursos.

La educación formal de la Comuna coexiste con estos procesos, pero a la fecha no han sido incorporados de manera sistemática de modo de contribuir a su discusión y a la transformación de prácticas sociales discriminatorias y racistas contra el mundo indígena y chango, así como frente a personas de otros países sudamericanos, recientemente llegadas a la localidad.

En la Comuna de Taltal existen seis establecimientos educacionales, todos dependientes del Departamento de Administración de Educación Municipal (DAEM) de la Municipalidad. Tres de ellos corresponden a Enseñanza Inicial (Parvularia) y Básica y se ubican en la capital urbana de Taltal, y un cuarto corresponde a una Escuela Rural en la localidad de Paposo. Además, Taltal cuenta con un Liceo Politécnico, un Liceo Humanista y seis jardines infantiles (PLADECO Taltal 20162022). "De acuerdo a los datos del PADEM, del total de profesores, el 48,9\% de ellos no tiene especialidad. De forma similar, el encargado comunal de la Seremía de Educación menciona que existe un bajo acceso de profesores a capacitaciones y perfeccionamiento, así como una débil gestión en nuevos profesores ya que la Comuna de Taltal no sería atractiva en el contexto profesional debido a los altos costos de la vida y escasez de vivienda" (PLADECO Taltal 2016-2022:62).

\section{Un Proyecto de Arqueología y Educación Formal en la Comuna de Taltal}

La investigación arqueológica en la que surge esta experiencia se ha desarrollado durante los últimos 
diez años en las localidades de Taltal y Paposo, y ha sido financiada por tres proyectos Fondecyt sucesivos. Durante su ejecución se realizaron diversas y esporádicas actividades de educación patrimonial y vínculos con la comunidad. Pero es a partir del año 2015 que se ha ido consolidando un proyecto de arqueología y educación formal que, en etapas sucesivas, ha incluido contenidos de relevancia local respecto a las identidades, modos de vida, territorio, prácticas sociales, prehistoria e historia local, dentro de los contenidos exigidos por los programas educativos oficiales para niveles de Transición 1 (Prekinder o NT1) a $2^{\circ}$ año Básico (Tabla 1). Lo anterior, por medio del diseño de experiencias de aprendizaje, así como sus planificaciones y los recursos didácticos necesarios para su implementación. El proyecto ha sido posible gracias a la ejecución de distintos convenios y alianzas con la Ilustre Municipalidad de Taltal y el DAEM local, el Departamento de Educación de la Universidad de Concepción, la Facultad de Ciencias Sociales de la Universidad de Chile, la Comunidad escolar taltalina y miembros de nuestro proyecto Fondecyt (Tabla 1).

Tabla 1. Síntesis comparativa de las principales características y limitaciones de las tres etapas de nuestro proyecto.

Comparative summary of the main characteristics and limitations of the three phases of the project.

\begin{tabular}{|c|c|c|c|}
\hline ITEM & $\begin{array}{l}\text { Periodo } 2015 \\
\text { Fondecyt } 1151203\end{array}$ & $\begin{array}{c}\text { Período 2016-2017 } \\
\text { Convenio Municipal-FACSO }\end{array}$ & $\begin{array}{c}\text { Período } 2018 \\
\text { Proyecto Explora ED210229 }\end{array}$ \\
\hline Propósito & $\begin{array}{l}\text { Demostrar la factibilidad que párvulos ( } 3 \\
\text { a } 5 \text { años) pudieran adquirir conocimientos } \\
\text { y actitudes respecto a la historia indígena } \\
\text { prehispánica y la preservación del } \\
\text { patrimonio cultural local, vinculando los } \\
\text { aprendizajes esperados con el curriculum } \\
\text { educacional. }\end{array}$ & $\begin{array}{l}\text { Transmitir a la comunidad escolar } \\
\text { ( } 3 \text { a } 6 \text { años) de Taltal y Paposo } \\
\text { conocimientos acerca de la historia e } \\
\text { identidad local a través de actividades } \\
\text { pedagógicas y lúdicas. }\end{array}$ & $\begin{array}{l}\text { Contribuir a la valorización de la historia } \\
\text { e identidad local de Taltal y Paposo en } \\
\text { educandos de los niveles de Transición I } \\
\text { a } 2^{\circ} \text { Básico ( } 4 \text { a } 8 \text { años), y en el personal } \\
\text { profesional y técnico que los asiste. }\end{array}$ \\
\hline $\begin{array}{l}\text { Actividades } \\
\text { contempladas }\end{array}$ & $\begin{array}{l}\text { Diseño e implementación de Estrategia de } \\
\text { Aprendizaje (EA), en las aulas beneficiadas } \\
\text { por el proyecto. }\end{array}$ & $\begin{array}{l}\text {-Confección de material didáctico } \\
\text { para ser utilizado en la enseñanza } \\
\text { del patrimonio de la Comuna de } \\
\text { forma permanente en las aulas } \\
\text { beneficiadas. } \\
\text {-Diseño e implementación de EA, } \\
\text { en las aulas beneficiadas por el } \\
\text { proyecto. } \\
\text {-Transposición didáctica dirigida } \\
\text { a docentes acerca de contenidos } \\
\text { de prehistoria e historia de Taltal } \\
\text { y Paposo. } \\
\text {-Visitas al Museo por parte de la } \\
\text { comunidad estudiantil. } \\
\text {-Visita a sitios arqueológicos por } \\
\text { parte de la comunidad de docentes. }\end{array}$ & $\begin{array}{l}\text {-Co-construcción con la comunidad } \\
\text { educativa de la Comuna (niveles } \\
\text { de Transición I a } 2^{\circ} \text { Básico) de una } \\
\text { secuencia didáctica y sus cuatro } \\
\text { propuestas didácticas inter-articuladas. } \\
\text {-Diseño de EA y confección de recursos } \\
\text { didácticos, manual de orientaciones } \\
\text { pedagógicas. } \\
\text {-Implementación de EA, en las aulas } \\
\text { beneficiadas por el proyecto. } \\
\text {-Transposición didáctica dirigida a docentes } \\
\text { acerca de contenidos de prehistoria e } \\
\text { historia de Taltal y Paposo. } \\
\text {-Visitas al Museo por parte de la } \\
\text { comunidad estudiantil y docentes. } \\
\text {-Visita a sitios arqueológicos por parte } \\
\text { de la comunidad de docentes. }\end{array}$ \\
\hline $\begin{array}{l}\text { Comunidad escolar } \\
\text { participante }\end{array}$ & $\begin{array}{l}\text { Número total de cursos participantes: } 2 \\
\text { Niveles: Medio Mayor y Transición I. } \\
\text { Público Objetivo: Educandos } \\
\text { Establecimientos: Jardines no } \\
\text { Municipales }\end{array}$ & $\begin{array}{l}\text { Número total de cursos } \\
\text { participantes: } 10 \\
\text { Niveles: Medio Mayor, Transición } \\
\text { I y Transición II. } \\
\text { Público Objetivo: Educandos } \\
\text { Establecimientos: Jardines y } \\
\text { Escuelas Municipales. }\end{array}$ & $\begin{array}{l}\text { Número total de cursos participantes: } 24 \\
\text { Niveles: Transición I, Transición II, } \\
1{ }^{\circ B} \text { ásico y } 2^{\circ} \text { Básico. } \\
\text { Público Objetivo: Educandos y docentes } \\
\text { Establecimientos: Escuelas Municipales. } \\
\text { Total de participantes: Estudiantes: } 771 \mid \\
\text { Docentes: } 28\end{array}$ \\
\hline $\begin{array}{l}\text { Número (n) de } \\
\text { profesionales } \\
\text { que participaron } \\
\text { en el diseño y/o } \\
\text { implementación. }\end{array}$ & $\begin{array}{l}\text { Educadora de Párvulo del Proyecto }(n=1) \\
\text { Asesores científicos }(n=2)\end{array}$ & $\begin{array}{l}\text { Educadora de Párvulo del Proyecto } \\
(\mathrm{n}=1) \\
\text { Licenciada en Educación de } \\
\text { Párvulo }(\mathrm{n}=1) \\
\text { Asesores científicos }(\mathrm{n}=2) \\
\text { Diseñador Gráfico }(\mathrm{n}=1) \text { e } \\
\text { Ilustradora }(\mathrm{n}=1)\end{array}$ & $\begin{array}{l}\text { Educadores y profesores participantes } \\
\text { del proyecto }(n=27) \\
\text { Especialistas en Educación Parvularia y } \\
\text { Básica }(n=5) \\
\text { Licenciadas en Educación de Párvulo } \\
(n=3) \text { y Básica }(n=3) \text {. } \\
\text { Asesores científicos }(n=4) \\
\text { Diseñadoras Gráficas }(n=2) \text { e } \\
\text { Ilustradora }(n=1)\end{array}$ \\
\hline $\begin{array}{l}\text { Tiempo de } \\
\text { Ejecución }\end{array}$ & $\begin{array}{l}\text { Una semana implementación de talleres } \\
\text { en aula. }\end{array}$ & $\begin{array}{l}10 \text { semanas implementación de } \\
\text { talleres en aula. }\end{array}$ & $\begin{array}{l}16 \text { semanas de codiseño. } \\
\text { Ocho semanas de implementación de } \\
\text { talleres en aula. }\end{array}$ \\
\hline $\begin{array}{l}\text { Experiencias de } \\
\text { Aprendizaje (EA) } \\
\text { implementadas }\end{array}$ & $\begin{array}{l}\text { Tres EA diseñadas por nivel e } \\
\text { implementadas en cada curso. }\end{array}$ & $\begin{array}{l}\text { Cinco EA diseñadas por nivel e } \\
\text { implementadas en cada curso. }\end{array}$ & $\begin{array}{l}12 \text { EA diseñadas por nivel e } \\
\text { implementadas en cada curso } \\
\text { tres talleres de co-construcción. }\end{array}$ \\
\hline $\begin{array}{l}\text { Principales } \\
\text { temáticas tratadas }\end{array}$ & Prehistoria indígena. & Prehistoria indígena. & $\begin{array}{l}\text { Prehistoria indígena e historia de Taltal } \\
\text { y Paposo. } \\
\text { Identidades locales. } \\
\text { Recursos naturales y territorio locales. }\end{array}$ \\
\hline
\end{tabular}


Continuación Tabla 1.

\begin{tabular}{|c|c|c|c|}
\hline $\begin{array}{l}\text { Principales } \\
\text { innovaciones } \\
\text { en comparación } \\
\text { a experiencias } \\
\text { anteriores }\end{array}$ & $\begin{array}{l}\text {-Participación de especialistas en Ed. } \\
\text { Parvularia en el diseño de experiencias } \\
\text { de aprendizaje. } \\
\text {-Generación de EA integradas a los } \\
\text { resultados esperados específicos de } \\
\text { reconocimiento de recursos, personas } \\
\text { relevantes a la historia del país. } \\
\text {-Se promueve respeto y orgullo de la } \\
\text { historia indígena local. }\end{array}$ & $\begin{array}{l}\text {-Integración de especialistas en } \\
\text { diseño gráfico. } \\
\text {-Generación de secuencias de } \\
\text { experiencias de aprendizaje } \\
\text { articuladas inter-nivel y EA } \\
\text { integradas en más de un resultado } \\
\text { de aprendizaje asociado a } \\
\text { contenidos de lógica y matemática } \\
\text { y/o lenguaje. } \\
\text {-Aumento en el número de } \\
\text { experiencias, distribuidas en un } \\
\text { período de tiempo. }\end{array}$ & $\begin{array}{l}\text {-Creación de una secuencia articulada } \\
\text { entre nivel. } \\
\text {-Participación de la comunidad de } \\
\text { Educadoras y Profesoras en el diseño e } \\
\text { implementación de EA. } \\
\text {-Aumento del número de EA agrupadas en } \\
\text { una unidad didáctica integrada a diversos } \\
\text { núcleos o asignaturas. } \\
\text {-Integración de contenidos de } \\
\text { territorio y recursos naturales. } \\
\text {-Participación de alumnas que cursan } \\
\text { técnico de Ed. Parvularia en las } \\
\text { actividades de diseño y transposición } \\
\text { didáctica. }\end{array}$ \\
\hline Observaciones & $\begin{array}{l}\text { No se generó material didáctico para } \\
\text { ser entregado a los jardines. } \\
\text { Experiencias esporádicas, con impacto en } \\
\text { el momento y no a largo plazo. }\end{array}$ & $\begin{array}{l}\text { - No se considera participación } \\
\text { por parte de las Educadoras de la } \\
\text { Comuna en el diseño de las EA. } \\
\text { Por lo tanto, las EA eran vistas } \\
\text { como actividades "extras" y } \\
\text { externas a los contenidos oficiales } \\
\text { que se deben cubrir. Externalizando } \\
\text { la labor en nuestra Educadora de } \\
\text { Párvulo. } \\
\text { - No hubo apropiación por parte } \\
\text { de las Educadoras de las EA, ni } \\
\text { recursos didácticos. }\end{array}$ & $\begin{array}{l}\text { - A la fecha no se ha considerado un } \\
\text { monitoreo de la implementación de las } \\
\text { unidades didácticas. } \\
\text { - A pesar que hubo un proceso de } \\
\text { codiseño no se realizaron talleres } \\
\text { prácticos de creación EA pertinentes y } \\
\text { contextualizadas para que las propias } \\
\text { Educadoras y Profesoras pudieran crear } \\
\text { otras unidades didácticas. } \\
\text { - Falta de la creación de un manual de } \\
\text { consulta que condense, de forma didáctica } \\
\text { y accesible a todo público información } \\
\text { científica integrada acerca del territorio, } \\
\text { recursos naturales y pre(historia) de la } \\
\text { Comuna. }\end{array}$ \\
\hline
\end{tabular}

\section{Primera Etapa: periodo 2015}

La primera etapa del proyecto surge en el año 2015 en el marco del proyecto Fondecyt 1151203. La iniciativa consistió en el diseño de una experiencia piloto en dos jardines infantiles no municipales de la ciudad de Taltal, la cual incluyó tres talleres de Educación Infantil. El objetivo de los talleres fue demostrar la factibilidad de que párvulos de los niveles de Medio Mayor y Transición 1 (tres a cinco años) pudieran adquirir conocimientos y actitudes respecto a la historia indígena prehispánica y la preservación del patrimonio cultural local, y su vez, vincular las enseñanzas con los aprendizajes esperados del curriculum educacional obligatorio en el sistema de educación inicial formal de Chile (Léniz 2017). Para ello, los talleres consistieron en la creación y ejecución de experiencias de aprendizaje acopladas en el ámbito de Relación con el Medio Natural y Cultural propuesto por las Bases Curriculares de Educación Parvularia (2001:81), específicamente en el aprendizaje esperado "Reconocer recursos y personas relevantes de la historia del país y del mundo, mediante relatos, narraciones, visitas, objetos y otros elementos representativos y significativos para su vida", núcleo "Grupos humanos, sus formas de vida y acontecimientos relevantes".

El diseño y ejecución de las experiencias y actividades en el aula incluyó la participación de una Educadora de Párvulos (Leniz 2017), quien trabajó en conjunto con miembros de nuestro proyecto Fondecyt, pero sin vinculación con profesionales o actores de la comunidad local. Los tres talleres se llevaron a cabo en una semana, en un total de cuatro cursos, y las actividades incluyeron básicamente lecturas compartidas de cuentos, trabajo con imágenes y la realización de juegos (Figura 2).
Los talleres tuvieron una muy buena aceptación por parte de las educadoras locales y la dirección de los establecimientos, especialmente por demostrar la posibilidad de incorporar contenidos de pertinencia local dentro del curriculum oficial, y por el alto interés y motivación que generaron las experiencias de aprendizaje en los propios educandos (Léniz 2017). Sin embargo, no se consideró la entrega de recursos didácticos en las aulas, ni la transposición didáctica de contenidos acerca de la pre(historia) de Taltal y Paposo a las Educadoras de Párvulo de los jardines que participaron en la actividad, lo cual no permitió la posterior replicación de las experiencias de aprendizaje por parte de las propias Educadoras de Párvulo. Pese a ello, la iniciativa también logró interesar a profesionales de la Unidad de Medioambiente de la Municipalidad de Taltal, ya que se vio en esta actividad una posibilidad real de potenciar la recuperación y valoración de la identidad local, apoyando de esta manera indirectamente el anhelo de algunas autoridades acerca del reconocimiento de la etnia "Changa" dentro de la Ley Indígena 19.253 que rige en Chile desde al año 1993. A partir de esta coyuntura, se gestionó un convenio entre la Municipalidad de Taltal y la Facultad de Ciencias Sociales de la Universidad de Chile, permitiendo una nueva fuente de financiamiento para darle continuidad a la iniciativa y profundizar sus alcances.

\section{Segunda Etapa: periodo 2016-2017}

La segunda etapa del proyecto, "Educación infantil para la valorización de la historia e identidad de los Changos", fue financiada y ejecutada en el marco del convenio previamente mencionado y aplicada en los 


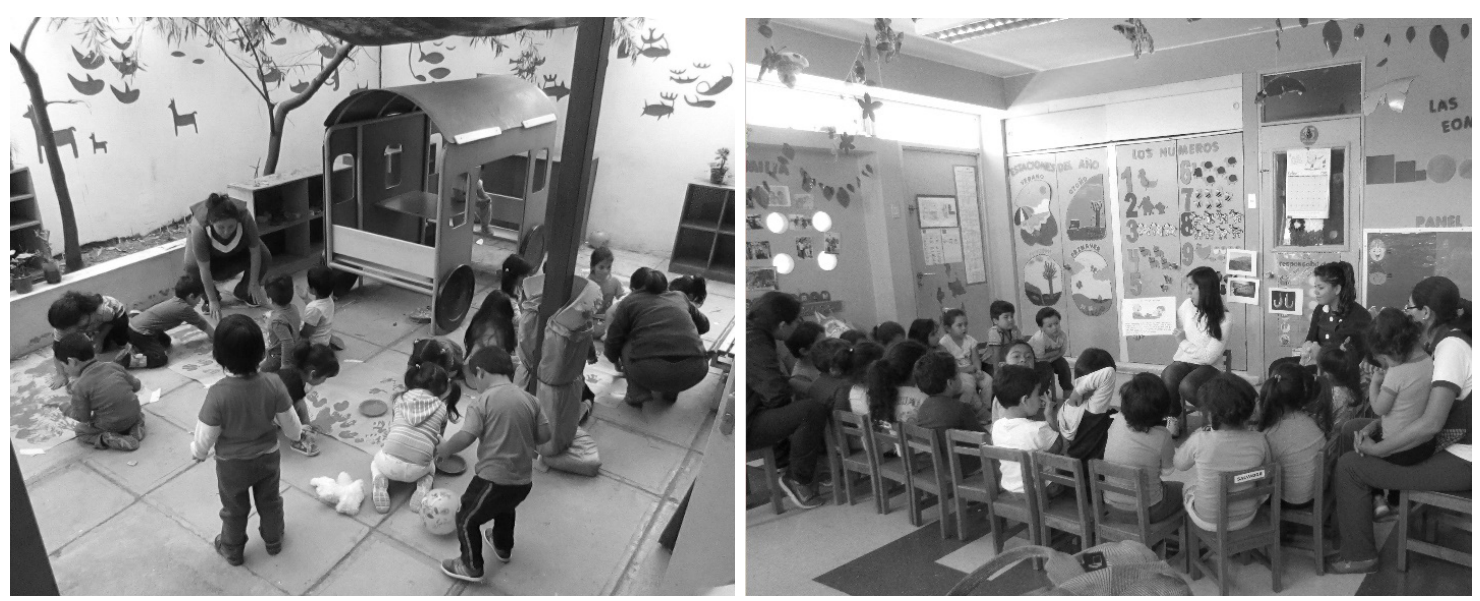

Figura 2. Realización de actividad de lectura compartida y reproducción de pictografías con niños y niñas en el año 2015.

Shared reading and reproduction of pictographs with children in 2015.

niveles de Medio Mayor a Transición 2 (tres a seis años), beneficiando un total de diez cursos pertenecientes a dos jardines infantiles y dos escuelas administradas por la Municipalidad de Taltal.

El diseño pedagógico y la implementación de las experiencias estuvieron a cargo de Educadoras de Párvulo de la Universidad de Concepción (Melo 2018) en colaboración con miembros de nuestro proyecto, uniéndose también al equipo diseñadoras gráficas del Instituto Profesional Duoc UC Concepción. Las experiencias de aprendizajes siguieron el modelo de planificaciones de la etapa anterior, pero en esta ocasión el objetivo fue demostrar la factibilidad de utilizar aprendizajes esperados de otros núcleos para fortalecer la historia e identidad local. Para ello las actividades se integraron en más de un objetivo de aprendizaje, tanto en los ámbitos de lenguaje, autonomía o relaciones lógico-matemáticas.

En el transcurso de 10 semanas, se realizaron un total de cinco experiencias de aprendizaje y una visita al museo por curso. Las actividades incluyeron lecturas compartidas, cuentos valóricos de cuidado del patrimonio, principios alfabéticos, actividades de clasificación, segmentación silábica, entre otras (Figura 3). Cada curso recibió su propio kit de recursos didácticos para que pudieran seguir implementándose las actividades a largo plazo.

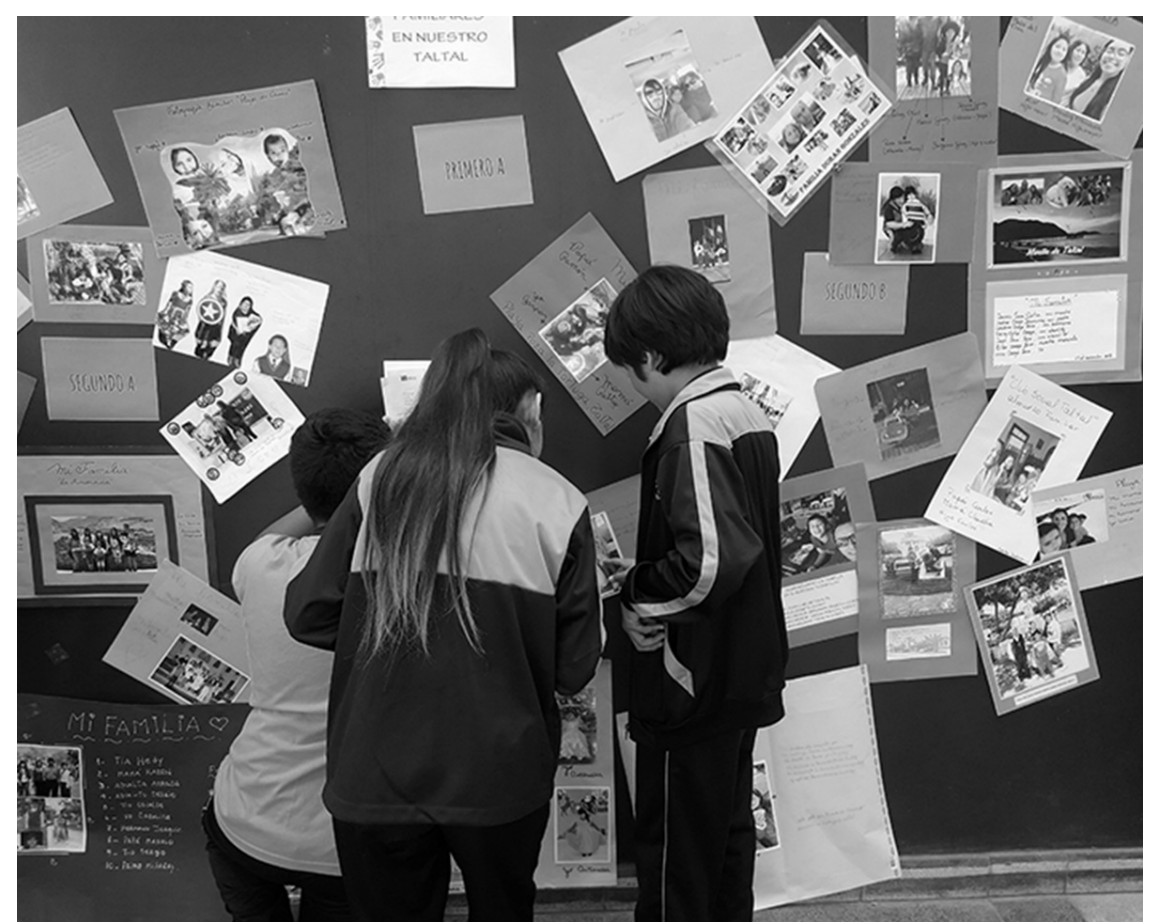

Figura 3. Exposición final actividades de "Momentos más importantes de mi vida" y "Árbol de Familia" en 2017. Final exposition of children research activities "Most important moments of my life" and "Family Tree". 
La experiencia estuvo a cargo de una licenciada en Educación Parvularia de nuestro equipo, quien se estableció por casi tres meses en Taltal, lo que permitió aumentar el número de experiencias a implementarse en aula. Si bien esta experiencia fue bien evaluada por las Educadoras de Párvulo y generó un impacto a nivel de la comunidad escolar, no promovió un empoderamiento y compromiso por parte de las docentes locales que permitiera darle continuidad temporal a este tipo de experiencias, debido a que, de acuerdo con sus propios testimonios, no se sentían capacitadas para enseñar acerca de la prehistoria, historia e identidades de la comuna (Melo 2018).

\section{Tercera Etapa: periodo 2018}

En una tercera etapa, nuestro proyecto se adjudicó un fondo concursable del Programa Explora de CONICYT (Proyecto Explora ED21029 "Educación Infantil para la valorización de la identidad e historia de Taltal y Paposo"), permitiéndonos expandir los objetivos y alcances del proyecto, aun cuando concentrándolos en las cuatro escuelas públicas de la Comuna.

El objetivo fue la creación de unidades didácticas de pertinencia local que se insertasen y tuviesen continuidad desde el nivel de Transición $1 \mathrm{a} 2^{\circ}$ año Básico (cuatro a ocho años). Además, se buscó afianzar las unidades didácticas en el modelo educativo municipal de Taltal, de modo de establecerlas como contenidos obligatorios a futuro, y especialmente para que sean ejecutadas por los profesores locales una vez que el proyecto finalice. Para ello, la propuesta se caracterizó por ser continua y progresiva, es decir, a medida que los educandos son promovidos al siguiente nivel educativo, los contenidos se van reforzando y profundizando. El diseño apuntó a realizar una transposición de contenidos académicos y no académicos para ser integrados en conjunción con otros contenidos obligatorios del curriculum propuesto por el MINEDUC, promoviendo de este modo saberes, tradiciones e historia locales y fomentando el arraigo y la valoración de lo local. De manera lúdica, esta estrategia permite focalizarse en el logro de aprendizajes significativos y situados, al mismo tiempo que se potencian habilidades y actitudes respecto de la propia realidad, incentivando la reflexión crítica.

Los contenidos seleccionados se integraron a diferentes núcleos de aprendizaje del curriculum. En Educación Inicial (Parvularia) se integraron en los núcleos de Convivencia y Ciudadanía, Lenguaje Verbal, Lenguajes Artísticos, Comprensión del Entorno Sociocultural y Pensamiento Matemático, mientras que en Enseñanza Básica en las asignaturas de Lenguaje y Comunicación e Historia, Geografía y Ciencias Sociales.

Las unidades didácticas fueron diseñadas por un equipo de especialistas en educación, arqueología y antropología, mientras que la creación de los materiales didácticos fue apoyada por una ilustradora y diseñadora gráfica. Cada unidad implicó la creación de estrategias que incluyesen diversas actividades lúdicas apoyadas por recursos didácticos, tales como cuadernos de trabajo del estudiante, guía didáctica para la Educadora de Párvulos o Profesor de Enseñanza Básica, y materiales específicos necesarios para ejecución de las actividades ${ }^{1}$.

En esta etapa del proyecto la comunidad educativa local participó en la co-creación de la propuesta pedagógica, así como en la selección de los recursos didácticos más adecuados a los objetivos de la misma. Para ello, se realizaron diversas jornadas de diálogo, discusión y transposiciones didácticas (Figura 4) de conocimientos académicos y no académicos sobre la realidad local, estrategias didácticas y sobre la misma propuesta pedagógica en su conjunto, incluyéndose salidas a terreno, visitas al museo y talleres conjuntos.

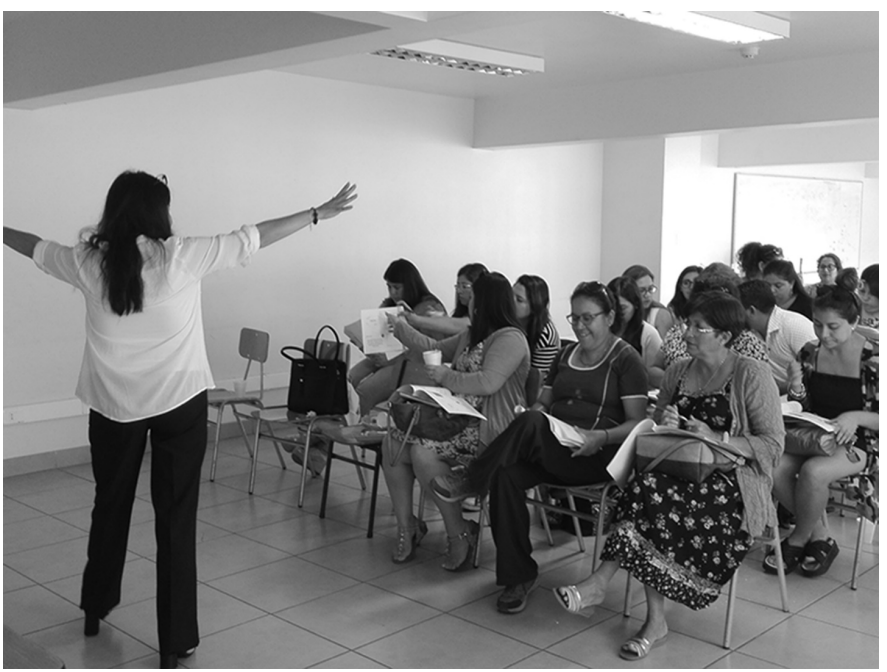

Figura 4. Jornada de co-construcción de la iniciativa con Educadoras de Párvulos y profesoras locales de la Comuna de Taltal, Proyecto Explora ED21029.

Co-construction workshop with preschool and local teachers of the Municipality of Taltal in 2018, Proyecto Explora ED21029. 
Las unidades didácticas co-construidas fueron implementadas durante cuatro semanas, en un total de 24 cursos, por seis personas de nuestro proyecto (tres licenciadas de Educación Inicial y tres licenciadas en Educación Básica). Después de la modelación de las primeras experiencias de aprendizaje, algunos docentes de la comuna decidieron implementarlas personalmente, lo cual nos permitió tener una retroalimentación efectiva respecto de la factibilidad de las unidades didácticas diseñadas, para así generar los últimos ajustes. Los manuales y recursos didácticos generados por el proyecto, quedaron a disposición de cada establecimiento educacional tanto físicamente como en formato virtual.

Una de las innovaciones de esta etapa fue la aplicación de un cuestionario KPSI (Knowledge and Prior Study Inventory; Young y Tamir 1977) antes y después de la intervención del proyecto, para identificar saberes previos de los y las docentes respecto de la historia, la prehistoria, el territorio y el patrimonio locales de la comuna. El cuestionario fue respondido de forma voluntaria y anónima por $23^{2}$ docentes de la Comuna de Taltal que participaban en el proyecto (de una población total de 27 Educadoras de Párvuloy Profesoras que trabajan con niveles de Nivel de Transición 1 a $2^{\circ}$ Básico en la Comuna de Taltal). El cuestionario evaluó planteamientos de nivel conceptual, procedimental y actitudinal, cuyas respuestas estaban categorizadas en una escala numérica del 1 al 4 . Se describieron por cada planteamiento, los porcentajes de casos por categoría de respuestas entregadas por las docentes antes y después de la intervención. De igual manera éstas también se compararon utilizando la prueba estadística U de MannWhitney (U). Para el control del error tipo I se consideró un $\alpha=0,05$ nivel de significación estadística. El procesamiento y análisis estadístico se realizó utilizando el paquete estadístico SPSS versión 25.0®. En la Tabla 2 se presentan los porcentajes atribuidos por categoría a cada planteamiento.

Tabla 2. Resultados de cuestionario KPSI aplicados en la Etapa 3 del Proyecto.

Results of the KPSI questionnaire administered during the third phase of the project.

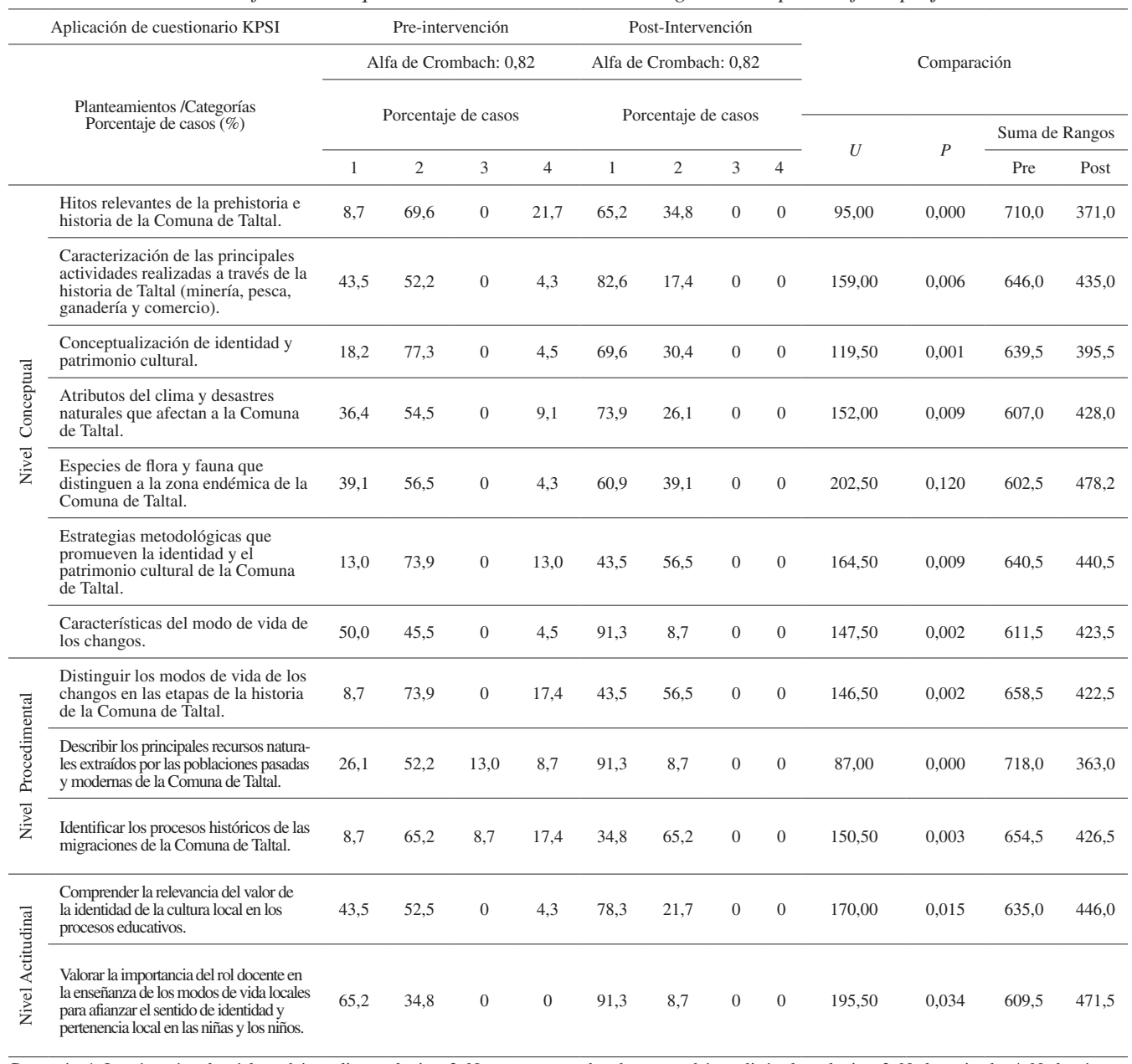


Al inicio de esta etapa el $91 \%$ de los docentes manifestaron que no estaban seguros de saber o no sabían acerca de los hitos de la prehistoria e historia local, por lo tanto no podían enseñar esas temáticas, mientras que en el caso de los conceptos de identidad y patrimonio cultural la misma situación fue reconocida por el $81 \%$ de docentes. Por su parte, un $87 \%$ no conocían estrategias metodológicas para la enseñanza de la identidad y patrimonio cultural local. Sin embargo, el $70 \%$ declaró que sabía y podía explicar el valor y la importancia que posee el rol docente en la enseñanza de los modos de vida locales para afianzar el sentido de identidad y pertenencia local en las niñas y niños.

De igual manera en esta etapa se aplicó una prueba de diagnóstico de contenidos a las niñas y los niños y se realizaron grupos focales y registro de diarios de la experiencia, resultados que no presentaremos, ni discutiremos en este trabajo por limitaciones de espacio. Sin embargo, es interesante mencionar que de acuerdo a los resultados obtenidos antes y después de la implementación el proyecto permitió una transposición didáctica de contenidos y aumentó los conocimientos técnicos de algunas materias, impactando también en cómo los educandos re-significan y valorizan sus propios saberes, lo cual promueve la apropiación real de los contenidos, no como una simple repetición memorística de contenidos.

\section{Discusión}

A partir de las experiencias previamente presentadas, organizaremos una discusión en torno a cuatro puntos que merecen un análisis más detallado para generar un diálogo reflexivo con otras iniciativas de "arqueología pública" en Chile y el mundo, y así contribuir a un análisis crítico respecto del abordaje de la dimensión social de la arqueología.

\section{Fundamentos didácticos}

Antes de implementar las experiencias presentadas en este trabajo, nuestros esfuerzos dentro del Proyecto Fondecyt por vincularnos con la comunidad local y generar un aporte a partir de los conocimientos generados por el proyecto, se limitaron a la realización de charlas en establecimientos educacionales, visitas guiadas a sitios arqueológicos tanto a estudiantes secundarios como a personas interesadas de Taltal, apariciones en los medios de comunicación locales (escritos y radiales), así como proporcionar materiales e información en las escuelas locales para que estudiantes de educación básica pudieran realizar réplicas de objetos arqueológicos durante las unidades con contenidos de "pueblos originarios" propuestas en los programa del MINEDUC.
En el mejor de los casos, estas experiencias generaron un aporte muy limitado, y en el peor de los casos, fueron sencillamente experiencias fallidas, ya que no generaron efectos concretos, en gran medida por no haber sido pensadas y diseñadas didácticamente. Muchas otras iniciativas de "arqueología pública" en el mundo comparten este negativo diagnóstico respecto de los reales alcances logrados por los proyectos (Merriman 2002), a pesar de las buenas intenciones que las motivaron. Luego de la fallida experiencia pionera del Museo del Hombre Venezolano (McGuire y Navarrete 1999), quizás la más importante iniciativa en la praxis de la Arqueología Social Latinoamericana, Sanoja y Vargas (1993:70) concluían que para alcanzar objetivos sociales, la arqueología "tendrá que teorizar y conocer los procesos de comunicación social y educación vía los museos, las exposiciones didácticas, las técnicas de interpretación y dramatización de los procesos históricos como una manera de transformar en materia didáctica su trabajo de investigador". Vale decir, una de las principales conclusiones de los gestores de esta iniciativa es la necesidad de integrar en los proyectos de "arqueología pública" miradas expertas respecto de los procesos de comunicación social y educación de modo de alcanzar los objetivos sociales propuestos.

Una década después de su publicación en español, teóricos de la "arqueología pública" inglesa llegaron a conclusiones similares:

Todos los modelos contemporáneos de comunicación muestran que [la difusión] se trata de un proceso doble, una transacción o negociación entre el receptor y el transmisor, la cual está filtrada por una serie de factores. Teniendo en cuenta el escaso conocimiento que los arqueólogos tienen acerca de las actitudes, concepciones y creencias que tienen los receptores de la información, se puede concluir que han estado comunicando ciegamente a una audiencia que no comprenden $\mathrm{y}$, por lo tanto, no debe extrañarnos que tantos esfuerzos por comunicar temas arqueológicos terminen en el aburrimiento o la incomprensión (Merriman 2004b:8; la traducción es nuestra).

Como puede apreciarse, nuevamente el énfasis está puesto en cómo realizar efectivamente un proceso de comunicación que permita transmitir un mensaje desde la arqueología hacia el "público".

En las últimas dos décadas la reflexión sobre estos procesos de comunicación ha sido más profunda en la literatura arqueológica anglosajona, la que ha comenzado a explorar teorías detrás de la nueva museología y, en menor medida, sobre el aprendizaje en general. En Chile son pocos los trabajos de "arqueología pública" que han considerado explícitamente teorías del aprendizaje como fundamentos conceptuales para definir estrategias de comunicación 
y "difusión", siendo importantes excepciones los trabajos de Córdova et al. (2002 y 2004), Meza (2010) y Aguilera (2015), quienes han demostrado desde la educación no formal lo ventajoso que es incorporar estrategias didácticas en el diseño de las iniciativas, pues éstas permiten anclar experiencias de aprendizaje que potencien la valorización de la historia, memoria y realidad local de forma significativa para los educandos.

Dado que es difícil que los arqueólogos logren especializarse en didáctica y comunicación social, la colaboración interdisciplinaria con la museología y, sobre todo, con profesionales de la educación, se torna indispensable para el éxito de un proyecto de "arqueología pública" que pretenda que los resultados de la investigación arqueológica tengan un efecto social.

En nuestro caso, el rol central jugado por la educación inicial y la educación básica en la colaboración interdisciplinaria del proyecto, ha permitido anclar las experiencias de aprendizajes de acuerdo con los resultados esperados por el MINEDUC, pero sobre todo diseñar propuestas didácticas adecuadas a los educandos, no solo incorporando contenidos, sino actitudes y habilidades relativas a la identidad local, el patrimonio y la historia.

\section{Participación local y co-creación}

Existe abundante literatura que demuestra que los proyectos de "intervención" pensados únicamente desde la academia o el aparato público generan a la larga un limitado efecto social, pues los propios actores locales ven la iniciativa como una intervención externa y desvinculada de sus propios intereses (Gassiot y Palomar (2000) para una síntesis del caso específico de la arqueología). Por otro lado, la crítica decolonial y las arqueologías indígenas han cuestionado duramente la producción de discursos arqueológicos sobre el pasado que luego se "difunden" al público, pues dichos discursos operan como mecanismos hegemónicos de "violencia epistémica" que marginan otras voces o discursos alternativos sobre el pasado (Gnecco 2008, 2012; Haber 2016; entre otros). Algunas de estas temáticas también han sido recogidas por la "arqueología pública" realizada en Chile (p.ej., Ayala 2008, 2017; Kalazich 2013). En el mundo anglosajón, por su parte, desde otras vertientes teóricas se ha llegado a consolidar lo que se ha dado en llamar "arqueología comunitaria", realizada con y para las comunidades locales (véase Atalay (2012) para una síntesis, y González-Ruibal (2014) para una visión crítica respecto a este tipo de arqueología).

En el proyecto que hemos desarrollado los procesos de participación local y de co-construcción de la propuesta también han sido considerados como fundamentales, pero no han operado en los términos que establecen las arqueologías comunitarias ni mucho menos la crítica decolonial. De hecho, los conocimientos sobre el territorio, la historia y las tradiciones locales incluidos en la propuesta pedagógica han sido aportados fundamentalmente por miembros académicos de nuestro proyecto Fondecyt.

En la tercera etapa del proyecto la participación local ha jugado un rol más relevante, y se ha concretado en dos niveles distintos y complementarios. Por una parte, mediante la inclusión de saberes locales en los contenidos de las propuestas didácticas, a pesar que éstos han sido recopilados por nuestra propia investigación etnográfica, la cual ha intentado identificar saberes, técnicas y tradiciones de la localidad, así como la percepción de ciertos actores claves acerca de los fundamentos más importantes de sus identidades, patrimonio y experiencia histórica.

El segundo nivel de participación local incluye a la comunidad educativa de la Comuna, tanto a educadores como a educandos. A partir de la tercera etapa, educadoras locales fueron partícipes en el proceso de construcción de las unidades didácticas. En particular, las docentes a cargo de los cursos intervenidos por el proyecto seleccionaron los objetivos de aprendizaje y orientaron cuáles se abordaban con mayor profundidad en sus establecimientos educacionales. Además, participaron como revisores y validadores de las unidades didácticas, permitiendo hacerlos partícipes de modo de crear unidades útiles para las necesidades educativas locales.

Desde el punto de vista de los educandos, participaron activamente gracias al enfoque didáctico-pedagógico asumido por el proyecto, basado en el constructivismo como teoría del aprendizaje, el cual plantea que el rol docente es ayudar a hacer consciente y sistemático este aprendizaje (Eggen y Kauchak 2012), siendo los propios educandos quienes juegan un rol activo de descubrimiento y reflexión en el desarrollo de su aprendizaje, dinamizando además procesos sociales al interior de sus propias comunidades inmediatas (familias) y locales (pueblo o ciudad).

Es evidente que las modalidades de participación contempladas en nuestro proyecto no cumplen con los estándares de las "arqueologías comunitarias" ni de la crítica decolonial. No obstante, creemos que es importante considerar el contexto en el que se desarrollan las iniciativas de "arqueología pública" para comprender las decisiones estratégicas que se toman en un proyecto, con sus consecuentes niveles de participación local.

En diversas conversaciones y entrevistas sostenidas con educadoras locales, las docentes manifestaron su interés en la propuesta que hemos desarrollado por considerarla relevante para la promoción de la identidad local y el arraigo territorial (Melo 2018). Algunos agentes políticos de la comunidad local también han apoyado el proyecto no por ver en él una expresión del multiculturalismo, sino que por sus posibilidades futuras de fomentar la agencia local y la defensa del territorio 
frente a intereses económicos exógenos (turismo, minería, etc.), articulándose con otras estrategias políticas más explícitas y con efectos en el corto plazo. No obstante, docentes y actores locales han señalado que se han visto limitados en sus posibilidades de ejercer un rol más activo en diseñar experiencias de aprendizaje en el ámbito de la educación formal, principalmente por la falta de tiempo, capacitación en estrategias didácticas, y conocimientos propios respecto a temas de historia, territorio y patrimonios locales. Esto sugiere que es poco probable que un proyecto como el aquí planteado pudiese surgir desde las propias bases y sin intervención externa.

Más aún, nuestro proyecto se ha desarrollado en distintas etapas, cada vez más amplias y ambiciosas, justamente porque se ha ido despertando el interés en los propios actores locales a partir de la ejecución de las dos primeras, en las cuales las propuestas y materiales didácticos venían completamente diseñados desde nuestro proyecto, y las experiencias de aprendizaje fueron ejecutadas por agentes externos a la comunidad local (nuestras educadoras). En la medida de que el potencial del proyecto ha sido reconocido y valorado por la comunidad escolar taltalina, hemos podido avanzar en dimensiones más profundas de colaboración y participación local para lograr, en la tercera etapa, que un grupo de docentes de la comuna implementaran por iniciativa propia las unidades didácticas diseñadas.

Sin embargo, la limitada disponibilidad de tiempo de la comunidad de docentes sigue siendo un factor clave que atenta contra su pleno involucramiento en el diseño de las unidades y estrategias didácticas del proyecto. A la fecha, hemos buscado un equilibrio entre las necesidades de desarrollar unidades didácticas en colaboración y co-construcción con educadoras y educadores locales, sin que les demande demasiado trabajo fuera del aula, pues ello implicaría una reacción negativa ante el proyecto dado que les supondría un exceso de carga y de trabajo.

Dado lo anterior, nos parece que una iniciativa que recoja los principios metodológicos de la "arqueología comunitaria" no es viable para los objetivos que nos hemos planteado como proyecto. Además, los propios actores locales han aprobado y apoyado los objetivos que persigue nuestro proyecto, e incluso nos han alentado a desarrollarlo e implementarlo. Por lo tanto, nuestra participación y control sobre el proyecto en tanto agentes externos a la comunidad no es necesariamente negativo, en la medida de que éste logre efectivamente cumplir con los objetivos y expectativas de actores locales. Por otro lado, esperamos que, eventualmente el proyecto quede completamente en manos de los actores locales, en la medida que se logre un proceso más profundo de participación e involucramiento de la comunidad educativa local. Para que ello ocurra será necesario generar el espacio y las modalidades que permitan que docentes locales puedan apropiarse y realizar modificaciones y actualizaciones permanentes a la propuesta didáctica elaborada por nuestro proyecto.

\section{Continuidad temporal}

El factor de continuidad temporal ha sido destacado como esencial por diversas iniciativas de "arqueología pública", tanto en Latinoamérica (p.ej., Montenegro 2012) como en el mundo anglosajón (p.ej., Moser et al. 2002; Tully 2007). En este último caso la necesidad de darle continuidad a los proyectos de arqueología pública se ha abordado por medio de contrataciones de tiempo completo de personas de las comunidades locales que puedan mantener los proyectos cuando el equipo de investigación no se encuentra en terreno. En nuestro proyecto, las necesidades de continuidad han sido abordadas de forma más compleja.

Por un lado, la implementación de las propuestas pedagógicas en aula estuvo a cargo de especialistas en educación de nuestro proyecto, aumentando en cada etapa tanto el número de personas implementando experiencias de aprendizajes en el aula, como la cantidad de éstas y el tiempo de su implementación, haciéndose de esta manera más evidente el efecto de nuestra intervención. Esta posibilidad permitió que el proyecto se desarrollara sin depender de la presencia del equipo completo en terreno, presencia que implica costos muy elevados para cualquier fuente de financiamiento externo.

En segundo lugar, la continuidad de la propuesta está pensada desde la perspectiva de la progresión del curriculum escolar. Vale decir, dado que la apropiación de contenidos, actitudes y habilidades por parte de los educandos se fortalece en la medida de que se refuerzan y reiteran sucesivamente (Maldonado 1998), la tercera fase de nuestro proyecto ha considerado su implementación en cuatro niveles progresivos de Enseñanza Inicial y Básica: Nivel Transición 1 (Prekínder), Nivel Transición 2 (Kínder), primer año y segundo año de Educación Básica. De este modo, la propuesta pedagógica ha considerado, como uno de sus principales ejes didácticos la continuidad de los aprendizajes a través de: (i) la secuenciación y progresión de los contenidos de pertinencia cultural referidos a la valorización del territorio y la historia local de Taltal y Paposo, lo que permite complejizar, de manera progresiva, el nivel de apropiación por parte de los estudiantes de los conceptos culturales, históricos y sociales esenciales para la construcción de la identidad y el arraigo territorial local; y, (ii) la secuenciación de los aprendizajes esperados del primer y segundo nivel Transición (NT1 y NT2) de Educación Inicial con los objetivos de aprendizaje de primer y segundo 
año de Educación Básica, lo que permite generar una progresión de las competencias lingüísticas, habilidades matemáticas y conocimiento histórico entre las unidades de cada nivel educativo.

En tercer lugar, la propuesta que hemos desarrollado apunta a su apropiación por parte de los propios profesores y educadoras locales. Lo anterior permite, por un lado, avanzar hacia un proceso reflexivo acerca de la propia práctica pedagógica de los y las docentes locales como tributaria al fortalecimiento de la identidad cultural y el arraigo al territorio y su historia de los educandos. Por otro lado, esperamos que garantice la continuidad de la propuesta pedagógica más allá de los proyectos de financiamiento que la han hecho posible, al ser los propios docentes locales quienes se encargarán de su implementación a futuro. Para lograr la apropiación por parte de los y las docentes locales de la propuesta pedagógica, aspecto considerado como uno de los nudos críticos del proyecto, se han considerado una serie de iniciativas tales como: (1) talleres de co-construcción y socialización de la propuesta pedagógica y de las estrategias y materiales didácticos; (2) jornadas de transposición de los contenidos de la propuesta y su implementación; (3) una guía de trabajo para educandos y docentes de los distintos niveles participantes; (4) materiales didácticos que son entregados en forma permanente a cada escuela participante de la iniciativa para su uso futuro; (5) un libro de difusión con contenidos más detallados acerca de la prehistoria, historia y realidad actual de Taltal y Paposo escrito especialmente para docentes locales, pero el cual aún no ha podido ser terminado; (6) versiones en digital de los libros y materiales para ser difundidas abiertamente de manera virtual.

Por último, aspiramos a que a futuro la iniciativa logre ser incorporada dentro de los planes educativos institucionales de cada establecimiento, lo que permitirá asegurar su continuidad con independencia de las personas que ejecuten las actividades. Si bien por el momento este nivel es sólo una aspiración, pues aún estamos en diálogo con el DAEM para que las propuestas pedagógicas sean consideradas en el PADEM (Plan de Desarrollo Educativo Municipal), su concreción garantizaría la continuidad del proyecto en el mediano y largo plazo, siendo esta una condición esencial para lograr efectos sociales reales y duraderos.

\section{Enfoque "crítico"}

El riesgo de discutir las ideas anteriores en forma segmentada, es que tiende a separar los aspectos prácticos y metodológicos de nuestro proyecto, de su dimensión más propiamente política. En esta separación parece residir la crítica que hacían Carrión et al. (2015) a las arqueologías públicas en Chile y, de modo más radical,
González-Ruibal (2014) a las arqueologías indígenas y poscoloniales.

Si echamos mano a la literatura para discutir la dimensión social y política de la arqueología pública, nos encontramos que las primeras iniciativas en el mundo anglosajón estuvieron principalmente ligadas a promover la protección del patrimonio arqueológico y a valorizar el rol de la arqueología en la sociedad contemporánea (Merriman 2002; Salerno 2013). De acuerdo con Matsuda (2016; véase también Matsuda y Okamura 2011), estas iniciativas pueden ser clasificadas bajo las categorías de "aproximaciones educativas" y "aproximaciones de relaciones públicas", respectivamente. Si bien en Latinoamérica y en Chile muchas iniciativas han perseguido también este tipo de objetivos, en nuestro continente también se advierte el desarrollo de enfoques críticos a lo menos desde los trabajos de la Arqueología Social Latinoamericana, e incluso desde antes (véase Salerno 2013 y réplicas de Lucio Menezes y de Henry Tantaleán para el caso Latinoamericano). Matsuda (2016) también ha reconocido la presencia de aproximaciones críticas en la arqueología pública anglosajona, haciendo un aporte interesante al separarlas de las aproximaciones "pluralistas" (multivocales), que son aún más frecuentes en el norte global y que se alinean funcionalmente con la lógica neoliberal y el multiculturalismo (véase también González-Ruibal 2014; Gnecco 2008, 2012; Ayala 2014, 2015 y 2017). Matsuda (2016) denuncia que las aproximaciones críticas han tendido a disminuir en el ámbito anglosajón a medida que ganan adeptos las aproximaciones pluralistas (véase también Clarke 2017).

En nuestro continente, la Arqueología Social Latinoamericana de los años 1970 y 1980 constituye posiblemente un extremo de los enfoques críticos en arqueología, ya que a partir de potenciar la dimensión pública y educativa de la disciplina se aspiraba a generar una "conciencia nacional" que sirviese de fundamento para la "transformación radical" del presente (Sanoja y Vargas 1993; Vargas 2006).

Nuestra propuesta es, en este sentido, mucho más modesta. No pretendemos contribuir a la generación de una "conciencia nacional", pues no nos parece un objetivo a nuestro alcance. Pero tampoco aspiramos simplemente a fortalecer las identidades locales dentro de una lógica multicultural. Lo que queremos lograr con este proyecto es contribuir a una educación inicial "situada" para las niñas y niños de Taltal y Paposo, fortaleciendo sus vínculos con el propio territorio, la realidad e historia locales, de modo de potenciar la formación de "sujetos históricos" (sensu Freire 2000) que forman parte de su historia y, por lo tanto, tengan también la posibilidad de incidir sobre ella y transformarla. Al situar el aprendizaje de la primera infancia en la realidad local, aspiramos que a futuro los actores locales alcances mayores 
grados de autoestima y arraigo que favorezcan su constitución como sujetos activos y protagonistas de sus propios procesos históricos. Siguiendo a Freire (2000), consideramos que las personas pueden constituirse en sujetos históricos justamente cuando reflexionan sobre sí mismas y toman consciencia de su propia realidad, la cual en su dimensión más inmediata es obviamente de escala local y regional, y solo secundariamente nacional e internacional.

Para lograr este objetivo no nos parece adecuado el enfoque "pluralista" o multivocal dominante en la arqueología pública anglosajona y en la arqueología multicultural latinoamericana (Gnecco 2012, 2014). Pensamos que las ciencias sociales pueden contribuir a comprender procesos históricos y actuales en las comunidades locales, y a fortalecer los vínculos de los agentes locales con ellos, fortaleciendo de este modo el pensamiento crítico. Más aún en localidades como Taltal y Paposo, donde no existe una fuerte identidad indígena depositaria de discursos ontológicos o epistemológicos propios. El desafío es cómo emplear los conocimientos académicos y los saberes locales no como verdades que se imponen sobre los educandos, sino como medios para su propia comprensión de la realidad local y el desarrollo del pensamiento crítico sobre ella.

Es en este sentido que tiene relevancia el trabajo etnográfico que ha buscado identificar y recopilar saberes y valores locales sobre historia, identidad y patrimonio. También es en este sentido que es relevante el empoderamiento de las propias educadoras locales, y sobre todo el desarrollo de propuestas pedagógicas en las que los educandos no sean receptores pasivos de la información, sino que se involucren activamente en el proceso de responder a preguntas y situaciones estimulantes planteadas por lo/as docentes, y que incluso involucren a sus familias y su comunidad en el proceso. Las estrategias didácticas implementadas en la tercera fase del proyecto apuntan justamente en esta dirección, ya que buscan que en las distintas unidades didácticas los estudiantes vivencien experiencias de aprendizaje desafiantes y significativas, desarrollando el pensamiento crítico.

Además, hemos intentado incorporar otras dimensiones críticas en la propuesta pedagógica desarrollada en la tercera fase de nuestro proyecto. En primer lugar, cautelar que la propuesta pedagógica no reproduzca categorías o estereotipos de género o étnicos, propios de la sociedad global eurocéntrica (Cosalan y Rebolledo 2017). Por ejemplo, planteando que todos los habitantes actuales de la zona son o descienden de migrantes. Asimismo, al presentar a los indígenas que habitaron en el pasado en Taltal y Paposo se ha evitado presentar a las mujeres como recolectoras y vinculadas a las tareas más domésticas, y a los hombres como los cazadores y vinculados a tareas más prestigiosas y activas. Para ello se ha realizado una revisión crítica tanto de los propios contenidos de las unidades pedagógicas, como de las ilustraciones que acompañan las actividades didácticas. Nos parece interesante destacar en este punto que la visión crítica no se funda solo en una posición ética, sino que también en saberes académicos que muestran, a partir de la información bioarqueológica, que mujeres y hombres no habrían sido excluidos del mismo tipo de actividad, incluyendo aquellas que demandaban un gran esfuerzo físico. Creemos que es la presencia de estas diferencias con el presente las que pueden ser usadas para estimular una comprensión crítica de la realidad por parte de los propios educandos.

En segundo lugar, hemos intentado promover la idea de que el "patrimonio" en la Comuna de Taltal y Paposo no está limitado a lo indígena y lo prehispánico, sino que a lo que las personas en el presente valoran como parte de su propia particularidad y herencia. Más aún, mostrando que no existe "una identidad" en Taltal y Paposo, y que la identidad indígena, localmente conocida como "chango", tampoco es uniforme ni estática en el tiempo y en el espacio.

Por último, el enfoque crítico que hemos buscado imprimirle al proyecto se relaciona con incorporar dentro del material de apoyo entregado a los educadores locales (p.ej., libro de difusión), alusiones explícitas a que la historia y la prehistoria reconstruidas desde la academia constituyen discursos en permanente cambio y revisión, y que existen diversos aspectos sobre los que no existe consenso o acuerdo en la actualidad ${ }^{3}$. Asimismo, tanto en las estrategias didácticas que componen la propuesta didáctica, como en las actividades complementarias realizadas por el proyecto con otros actores sociales, intentamos rescatar el valor de los saberes locales respecto de la propia realidad local y su historia reciente. La idea es que tanto los educandos como adultos de la comunidad contribuyan a la comprensión de su historia reciente a través de aportar con saberes familiares y reconocimientos del valor de dichos saberes y de sus depositarios.

\section{Conclusiones:}

\section{Más que “Arqueología y Educación”, más que "Arqueología Pública"}

La arqueología pública es un campo actualmente amplio y complejo que desafía cualquier intento de síntesis (Clarke 2017). Existe literalmente un sinnúmero de iniciativas de este tipo en todo el mundo, una parte pequeña de las cuales llegan a publicarse en círculos académicos. Pese a las numerosas limitaciones y críticas que se han formulado respecto de la "arqueología pública" (p.ej., Gnecco 2012; González-Ruibal et al. 2018; Moshenska 2008; entre otros), muchas de estas iniciativas buscan generar un verdadero aporte social desde la arqueología. Es muy posible que sea en el campo de la educación no formal donde se hayan 
logrado los efectos sociales más significativos. Al menos, la literatura disponible en Chile demuestra que es allí donde se han llevado a cabo las iniciativas más creativas y comprometidas con las realidades locales (p.ej., Aguilera 2015; Aguilera et al. 2006; Córdova et al. 2004; Godoy et al. 2003; entre otros).

En complemento con este tipo de iniciativas, creemos que existe un enorme campo potencial para generar aportes sociales desde la arqueología, si ésta se vincula también con la educación formal. De hecho, la educación formal parece proveer soluciones para algunos de los principales problemas y obstáculos a los que se enfrentan los proyectos de "arqueología pública", tales como la falta de continuidad en el tiempo de los proyectos, lo que genera "esfuerzos aislados y efímeros" (Montenegro 2012:495), o la necesidad de colaborar con actores sociales locales para que den continuidad y sentido a las iniciativas (Moser et al. 2002). Asimismo, permite alcanzar audiencias más amplias que las logradas generalmente en proyectos de "arqueología pública" (Cosalan y Rebolledo 2017) y asegurar recursos permanentes para la implementación de las propuestas, al integrarse en la institucionalidad vigente financiada por el Estado.

Buscar el vínculo con la educación formal en los niveles iniciales de formación parece ser una estrategia necesaria, pues está bien demostrado que es durante la infancia cuando se afianzan nociones de identidad personal y social en las personas, por lo tanto, se cementan concepciones acerca de uno mismo, los otros y el territorio habitado, incluyendo los valores y principios que determinarán la conducta individual y social en el futuro (Melo 2018; Young 1995). Por ello creemos que en los niveles iniciales de la educación formal es posible influir en la formación de valores de tolerancia, democracia y pensamiento crítico que aspiramos fundamenten nuestra vida en sociedad.

No obstante, al revisar la literatura sobre arqueología y educación formal, uno se encuentra reiteradamente con la afirmación, no sin cierto grado de melancolía, de que existen muy pocos contenidos de arqueología en los currículos oficiales que estructuran la educación formal (Cole 2014; Erickson 2011; García 2007; Montenegro 2012; Stone y McKenzie 1990). Pero quizás la discusión esté mal enfocada. Desde nuestro punto de vista, no es necesario modificar los currículos oficiales para que la arqueología tenga un espacio más definido y protagónico dentro de ellos. Lo que interesa es que dicho curriculum recoja la experiencia histórica y la realidad local de las propias comunidades, y en ese sentido la arqueología puede jugar o no un rol, según sea el caso. La retórica multicultural ya ha abierto espacios dentro de los currículos oficiales para potenciar una formación inicial centrada en las realidades locales y el arraigo territorial y cultural de los educandos (Cosalan y Rebolledo 2017; Vergara 2008). Por lo tanto, lo que podría hacer la arqueología en el corto plazo es profundizar en una reflexión pedagógica que permita identificar los objetivos de aprendizajes donde los conocimientos sobre el pasado sean relevantes, y desarrollar las estrategias didácticas que permitan potenciar la formación de sujetos históricos localmente situados a partir de dichos aprendizajes. Para ello parece necesario cumplir con algunos requisitos mínimos: (i) identificar aquellos conocimientos tanto académicos como locales que tienen mayor potencial para vincularse con el presente de las comunidades locales, (ii) diseñar estrategias pedagógicas que sean adecuadas en términos de la generación de aprendizajes significativos; (iii) insertar tales conocimientos en los objetivos de aprendizaje de los currículos oficiales, y (iv) garantizar la continuidad en el tiempo de las propuestas pedagógicas diseñadas. Considerando lo anterior, un proyecto que cumpla con tales condiciones, como el que estamos tratando de implementar en las localidades de Taltal y Paposo, es más que una iniciativa de "arqueología y educación formal" o incluso de "arqueología pública". Sin duda que la investigación en la que surge nuestro proyecto es arqueológica, que parte importante de la información aportada a la propuesta pedagógica proviene de la investigación arqueológica. No obstante, el proyecto debe ser también más que eso para lograr sus objetivos principales.

Nos referimos, por una parte, a la necesidad imperiosa de realizar colaboraciones interdisciplinarias con especialistas en educación, historia, etnografía, patrimonio y diseño, entre otros (Sanoja y Vargas 1993), así como con actores de las propias comunidades locales, incorporando sus saberes y tradiciones. Pero, por otro lado, nos referimos a la necesidad de aceptar que si lo que queremos es potenciar la formación de sujetos históricos, entonces la información arqueológica es sólo un medio, no un fin en sí mismo. Y ni siquiera es un medio crucial, pues tanto o más importante que la información arqueológica, es la información histórica, etnográfica y los saberes locales, pues en torno a ellos es más fácil generar vínculos afectivos y cognitivos, favoreciendo el aprendizaje significativo y la reflexión situada.

Agradecimientos: Este proyecto ha sido financiado por los proyectos Explora CONICYT de Valoración y Divulgación de la Ciencia y la Tecnología 2017 -2018 ED210229, Fondecyt 1151203, y por el convenio entre la Municipalidad de Taltal y la Facultad de Ciencias Sociales de la Universidad de Chile. Deseamos expresar nuestro profundo y sincero agradecimiento a todos y todas quienes han hecho posible esta iniciativa. A las autoridades de la Municipalidad de Taltal, en especial a Carlos Iriarte, Director de la Unidad de Medioambiente, a Lorenzo Rojas Tabilo, Jefe del DAEM-Taltal, a Carola Valdivia, Encargada de la Unidad de Patrimonio y Turismo, a Sergio Orellana, Alcalde de la Ilustre Municipalidad 
de Taltal y a todo el Consejo Municipal. Asimismo, a directivos y docentes de las escuelas Victor Hugo Carvajal Meza, Alondra Barrios y Victoriano Quinteros Sotos y la Escuela Paranal de Paposo, por permitirnos desarrollar esta iniciativa e involucrarse en su diseño y ejecución. A María Elena Acuña, de la Facultad de Ciencias Sociales de la Universidad de Chile por el respaldo dado a la propuesta. Por último, a las educadoras Laura Léniz y Jennifer Melo, quienes participaron en las primeras etapas del proyecto, y a todo el equipo Fondecyt 1151203, por su compromiso con la reconstrucción de la prehistoria de Taltal y Paposo, y por sus aportes al desarrollo de esta iniciativa. Agradecemos también a los evaluadores anónimos por sus aportes y comentarios.

\section{Referencias Citadas}

Adán L., M. Uribe, M. Godoy, C. Jiménez y D. Salazar 2001. Uso del patrimonio cultural en la construcción de memorias e identidades históricas nacionales. Actas del IV Congreso Chileno de Antropología Tomo 1, pp. 619-629. Colegio de Antropólogos de Chile, Santiago.

Aguilera, D. 2007. Patrimonio cultural e identidad local: el caso de La Ligua. Actas del VI Congreso Chileno de Antropología Tomo 2, pp. 1366-1378. Colegio de Antropólogos de Chile, Santiago.

Aguilera, D. 2015. Arqueología y didáctica para niños y niñas en el museo La Ligua. Actas del XIX Congreso Nacional de Arqueología Chilena, pp. 327-332. Andros Impresiones, Santiago.

Aguilera, D., D. Pavlovic y E. Aguayo 2006. Educación patrimonial: la experiencia del sitio Quínquimo. Actas del XVI Congreso Nacional de Arqueología Chilena, pp. 687-694. Ediciones Escaparate, Concepción.

Aguilera, D y C. Prado 2010. Educación patrimonial y arqueología: aportes desde el Museo de La Ligua. Actas del XVII Congreso Nacional de Arqueología Chilena. Tomo 1, pp. 549-558. Ediciones Escaparate, Concepción

Ajagán, L. y O. Turra 2009. El texto escolar: hacia una didáctica crítica. Revista de Estudios y Experiencias en Educación 8 (16):87-99.

Almansa-Sánchez, J. (ed.) 2013. Arqueología Pública en España. JAS Arqueología SLU, Madrid.

Artigas, D. y P. Salatino 2009. Piedras, miradas y discursos: el arte rupestre a los ojos de las localidades de Césped y Los Perales, Illapel, Chile. Actas del Congreso Internacional de Arte Rupestre, pp. 1057-1071. IFRAO, Teresina.

Atalay, S. 2012. Community-Based Archaeology. Research with, by, and for Indigenous and Local Communities. University of California Press, Los Ángeles.

Ayala, P. 2008. Políticas del Pasado: Indígenas, Arqueólogos y Estado en Atacama. Línea Editorial IIAM/Universidad Católica del Norte, San Pedro de Atacama.

Ayala, P. 2014. Patrimonialización y arqueología multicultural en San Pedro de Atacama (Norte de Chile). Estudios Atacameños 49:69-94.

Ayala, P. 2015. Neoliberal multiculturalism and contract archaeology in Northern Chile. International Journal of Historical Archaeology 19 (4):775-790.

Ayala, P. 2017. Arqueología y pueblos indígenas en Chile los casos Aymara, Atacameño, Mapuche y Rapa Nui. Boletín de la Sociedad Chilena de Arqueología 47:69-92.

Ayala, P., S. Avendaño y U. Cárdenas 2003. Vinculaciones entre una arqueología social y la comunidad indígena de Ollagüe, II Región. Chungara Revista de Antropología Chilena 35 (2):275-285.

Bianco, M., N. Gras y J. Sutz 2014. Reflexiones sobre la práctica de la evaluación académica. En Veinte Años de Políticas de Investigación en la Universidad de la República:
Aciertos, Dudas y Aprendizajes, editado por M. Bianco y J. Sutz, pp. 209-235. CSIC-TRILCE, Montevideo.

Bravo, L. 2015. Arqueología en el aula: buscando una efectiva aplicación del conocimiento arqueológico en la comunidad atacameña, por medio de una webquest. Actas del XIX Congreso Nacional de Arqueología Chilena, pp. 301-306. Andros Impresiones, Santiago.

Carrasco, C. 2006. La práctica arqueológica y la actual construcción de conocimiento arqueológico en Chile. Boletín de la Sociedad Chilena de Arqueología 39:35-50.

Carrasco, C., C. Agüero, P. Ayala, M. Uribe y B. Cases 2003. Investigaciones en Quillagua: Difusión del conocimiento arqueológico y protección del patrimonio cultural. Chungara Revista de Antropología Chilena 35 (2):321-326.

Carrión, H., C. Dávila, A. Delgado, N. Fuenzalida, P. Kelly, F. Moya, S. Rebolledo, S. Sierralta, J. Sepúlveda y C. González 2015. Evaluación de la arqueología social en Chile: desarrollo histórico y revisión crítica del proyecto disciplinar. Boletín de la Sociedad Chilena de Arqueología 45:95-114.

Celorio, J. y A. Goñi 1989: Pautas de investigación en didáctica de las ciencias sociales. Revista Interuniversitaria de Formación del Profesorado 6:53-61.

Clarke, D. 2017. Public archaeology: narrowing the perspective, enlarging the ambition. Public Archaeology 15:136-140.

Cole, T. 2014. Towards anAssessment of the Value of Archaeological Education for Primary School Pupils. Tesis Doctoral. University College London, London.

Corbishley, M. y P. Stone 1994. The teaching of the past in formal school curricula in England. En The presented Past Heritage, Museums and Education, editado por P. Stone y B. Molyneaux, pp. 383-397. Routledge, Londres.

Córdova, J., Y. Ossandon, N. Álvarez y J. Bernal 2002. De las sociedades Chinchorro al presente. Un enfoque de ciencia y tecnología en educación de museo. Chungara Revista de Antropología Chilena 34 (1):127-140.

Córdova, J., Y. Ossandon, N. Álvarez y J. Bernal 2004. E museo arqueológico en la dinámica cultural de ver y aprender. Chungara Revista de Antropología Chilena Vol. 36 (suplemento especial) Tomo 2:687-696

Cosalan, A. y S. Rebolledo 2017. Exploring perceptions: representations of indigenous communities in Chilean and Philippine formal education. En Sustainability and Sociocultural Matrices. Transdisciplinary Contributions for Cultural Integrated Landscape Management, editado por L. Oosterbeek, B. Werlen y L. Caron, Vol 2, pp. 227-238. Arkeos 41, Mação.

Delfino, D.D. y P.G. Rodríguez 1991. Crítica de la Arqueología 'Pura': De la Defensa del Patrimonio Hacia una Arqueología Socialmente Útil. Escuela Politécnica de Guayaquil, Quito. 
Donoso, S., F. Garrido, F. Rivera, R. Lorca, M.J. Fernández, R. Moyano y A. Sejas 2010. Conocer para preservar: una experiencia de trabajo patrimonial en el parque nacional Pan de Azúcar. Actas del XVII Congreso Nacional de Arqueología Chilena Tomo 1, pp. 209-2016. Ediciones Kultrún, Valdivia.

Eggen, P.D. y D.P. Kauchak 2012. Estrategias Docentes: Enseñanza de Contenidos Curriculares y Desarrollo de Habilidades de Pensamiento. Tercera Edición, Fondo de Cultura Económica, México DF.

Erickson, A. 2011. Outreach and education in archaeology. Online Journal in Public Archaeology 1:45-54.

Freire, P. 2000. Pedagogía del Oprimido. Siglo XXI Editores, Madrid.

García, N. 2007. Arqueología y educación. Estado de la cuestión. Cuicuilco 14 (39):203-226.

Gassiot, E. y B. Palomar 2000. Arqueología de la praxis: información histórica de la acción social. El caso de la Unión de Cooperativas Agropecuarias de Miraflor, Nicaragua. Complutum 11:87-99.

Gnecco, C. 2008. Manifiesto moralista por una arqueología reaccionaria. En Puentes Hacia el Pasado: Reflexiones Teóricas en Arqueología, editado por D. Jackson, D. Salazar y A. Troncoso, pp. 23-32. Serie Monográfica de la Sociedad Chilena de Arqueología 1, Santiago.

Gnecco, C. 2012. Arqueología multicultural. Notas intempestivas. Complutum 23 (2):93-102.

Gnecco, C. 2014. Multivocalidad, años después. En Multivocalidad y Activaciones Patrimoniales en Arqueología: Perspectivas desde Sudamérica, editado por M.C. Rivolta. M. Montenegro, L. Menezes y J. Nastri, pp. 35-46. Fundación de Historia Natural Félix de Azara, Buenos Aires.

Godoy, M. y L. Adán 2003. Educación patrimonial en el trabajo de campo arqueológico. Revista Austral de Ciencias Sociales 7:139-152.

Godoy, M., J. Hernández y L. Adán 2003. Educación patrimonial desde el museo: iniciativas de promoción y puesta en valor del patrimonio cultural en la X Región. Conserva 7:23-36.

Gómez, A. 2004. Un camino de aproximación a las ciencias sociales: la didáctica museográfica. Revista de Teoría y Didáctica de las Ciencias Sociales 9:143-168.

Gómez, A. y F. Ocaranza 2012. Diagnóstico inicial de las problemáticas teóricas y metodológicas en la enseñanza de la prehistoria en el contexto escolar y en la Educación Superior en Chile. Revista Tradición y Saber 9:35-50.

Gómez, C., C. Prado y F. Ocaranza 2015. Incidencia de la arqueología en la formación inicial docente: problemas epistémicos, competencias profesionales docentes e influencia del discurso disciplinar arqueológico. Actas del XIX Congreso Nacional de Arqueología Chilena, pp. 333-337. Andros Impresiones, Santiago.

González, C., C. Westfal y C. Castells 2010. Investigación, conservación y puesta en valor del patrimonio arqueológico asociado al proyecto minero Damiana, El Salvador, región de Atacama. Boletín Museo Regional de Atacama 1:63-87.

González-Ruibal, A. 2014. Malos nativos. Una crítica de las arqueologías indígenas y poscoloniales. Revista de Arqueología 27 (2):47-63.

González-Ruibal, A., P. Alonso-González y F. Criado-Boado 2018. Against reactionary populism: towards a new public archaeology. Antiquity 92 (362):507-515.
Haber, A. 2016. Decolonizing archaeological thought in South America. Annual Review of Anthropology 45:469-485.

Henson, D. 2017. Archaeology and education. En Key Concepts in Public Archaeology, editado por G. Moshenska, pp. 43-59. UCL Press, Londres.

Holl, A. 1995. African history: past, present and future. The unending quest for alternatives. En Making Alternative Histories. The Practice of Archaeology and History in NonWestern Societies, editado por P. Schmidt y T. Patterson, pp. 183-212. School of American Research Press, Santa Fe.

Instituto Nacional de Estadísticas 2018. Estimaciones y proyecciones de la población de Chile 1992-2050. Total País. Metodología y principales resultados. www.censo2017.cl

Jofré, D. 2012. Arqueología, comunidades y monumentos en la Biosfera Lauca: posibilidades de la práctica de la arqueología social en el norte de Chile. En La Arqueología Social Latinoamericana: de la Teoría a la Praxis, editado por H. Tantaléan y M. Aguilar, pp. 415-432. Universidad de Los Andes, Colombia.

Kalazich, F. 2013. Cultural Meanings and Values of the past. A Participatory Approach to Archaeology in the Atacameño Community of Peine, Chile. Tesis Doctoral. Institute of Archaeology, University College London, London.

Ladrón de Guevara, B., N. Gaete y S. Morales 2003. El patrimonio como fundamento para el desarrollo del capital social: el caso de un sitio arqueológico y Puntilla Tenglo. Conserva 7:5-22.

Léniz, L. 2017. La Preservación del Patrimonio Cultural Taltalino. Propuesta para la Valoración de la Historia e Identidad de los Changos en el Nivel de Educación Parvularia. Proyecto Educativo para optar al grado de Magister en Educación. Universidad de Concepción, Concepción.

Leone, M., P.B. Potter y P. Schakel 1987. Towards a critical archaeology. Current Anthropology 28 (3):283-302.

Lorenzo, J.L., L. Lumbreras, E. Matos, J. Montané y M. Sanoja 1976. Hacia una Arqueología Social. Reunión en Teotihuacán. Instituto Nacional de Antropología e Historia, México DF.

Maldonado, A. 1998. Aprendizaje, Cognición y Comportamiento Humano. Biblioteca Nueva, Madrid.

Matsuda, A. 2016. A consideration of public archaeology theories. Public Archaeology 15 (1):40-49.

Matsuda, A. y K. Okamura 2011. Introduction: New Perspectives in Global Public Archaeology. En New Perspectives in Global Public Archaeology, editado por K. Okamura y A. Matsuda, pp. 1-18. Springer, New York.

McGuire, R. y R. Navarrete 1999. Entre motocicletas y fusiles: las arqueologías radicales Anglosajona y Latinoamericana. Boletín de Antropología Americana 34:89-110.

Melo, J. 2018. La Enseñanza del Patrimonio Cultural en la Educación Parvularia. Un Análisis desde las Bases Curriculares y la Experiencia de Educadoras de la Comuna de Taltal, Región de Antofagasta. Seminario para optar al grado de Licenciado en Educación. Facultad de Educación, Universidad de Concepción, Concepción.

Merriman, N. 2002. Archaeology, heritage and interpretation. En Archaeology: The Widening Debate, editado por B. Cunliffe, W. Davies y C. Renfrew, pp. 541-566, Oxford University Press, London.

Merriman, N. (ed.) 2004a. Public Archaeology. Routledge, Londres. 
Merriman, N. 2004b. Introduction: diversity and dissonance in public archaeology. En Public Archaeology, editado por N. Merriman, pp. 1-18. Routledge, Londres

Meza, D. 2010. Rescatando la Memoria Colectiva de la Comunidad del Jardín Infantil Sagrada Familia de Pudahuel. Tesis para optar al grado de Licenciatura en Conservación y Restauración de Bienes Culturales Museables. Universidad Internacional SEK, Santiago.

MINEDUC 2001. Bases Curriculares de la Educación Parvularia Unidad de Curriculum y Evaluación. Ministerio de Educación, Chile. Maval Ltda., Santiago.

Montenegro, M. 2012. Arqueología en la escuela: Experiencias en el sector septentrional del noroeste argentino. Chungara Revista de Antropología Chilena 44 (3):487-498.

Moser, S., D. Glazier, J. Philips, L. El Nemer, M. Mousa, S. Richardson, A. Conner y M. Seymour 2002. Transforming archaeology through practice: strategies for collaborative practice in the Community Archaeology Project at Quseir, Egypt. World Archaeology 34 (2):220-248.

Moshenska, G. 2008. Community Archaeology from below: a response to Tully. Public Archaeology 7 (1):51-52.

Moshenska, G. 2017a. Key Concepts in Public Archaeology. UCL Press, Londres.

Moshenska, G. 2017b. Introduction: public archaeology as practice and scholarship where archaeology meets the world En Key Concepts in Public Archaeology, editado por G. Moshenska, pp. 1-13. UCL Press, Londres.

Okamura, K. y A. Matsuda (eds.) 2011. New Perspectives in Global Public Archaeology. Springer, New York.

Opazo, C. 2016. Arqueología y patrimonio: "Arqueoniños", una propuesta de vinculación entre la ciencia arqueológica y la comunidad escolar en el Museo Histórico Nacional. Actas del VI Congreso Educación, Museos y Patrimonio: Calidad, Equidad e Inclusión, pp. 44-51. CECA- ICOM Chile/DIBAM, Santiago.

Pascual, D. 2010. Patrimonio y comunidad: una experiencia en la Comuna de Freirina. Actas del XVII Congreso Nacional de Arqueología Chilena Tomo 1, pp. 277-284. Ediciones Kultrún, Valdivia.

Pladeco Taltal 2016-2022. 2015. Ilustre Municipalida de Taltal y POCH Consultores https://portal.municipalidadtaltal.cl/images/ PLADECO_TALTAL_2016-2022_POCH_AMBIENTAL.pdf (3 de enero 2019)

Podgorny, I. 2000. Archaeology and education in Argentina. Antiquity 74:151-155.

Romero, A. 2003. Arqueología y pueblos indígenas en el extremo norte de Chile. Chungara Revista de Antropología Chilena 35 (2):337-346.

Romero, A., R. Ajata, G. Espinosa y L. Briones 2004. Arqueología pública y comunidades rurales: un proceso de puesta en valor en el valle de Codpa, región de Tarapacá. Boletín Museo Gabriela Mistral de Vicuña 6:42-63.

Romero, A. P. Casanova y J. Barraza 2015. Planes de manejo para la puesta en valor de yacimientos arqueológicos: experiencias en el extremo norte de Chile. Actas del XIX Congreso Nacional de Arqueología Chilena, pp. 321-326. Andros Impresiones, Santiago.

Salatino, P. y D. Artigas 2011. Materialidad arqueológica, práctica científica y activación patrimonial en la Cuenca del Choapa, IV región, Chile. Comechingonia 15 (1):139-154.
Salatino, P. y A. Troncoso 2014. Patrimonio arqueológico y memorias de la colonialidad/modernidad en el valle de Limarí (centro norte de Chile). En Patrimonio y Multivocalidad. Teoría, Práctica y Experiencias en torno a la Construcción del Conocimiento en Patrimonio, coordinado por C. Gianotti, D. Barreiro y B. Vienni, pp. 95-114. Ediciones Universitarias, Montevideo.

Salazar, D. 2010. Comunidades indígenas, compañías mineras y arqueología en el norte grande de Chile: ¿hacia un diálogo posible? En Pueblos Indígenas y Arqueología en Latinoamérica, editado por C. Gnecco y P. Ayala, pp. 221-258. Universidad de Los Andes, Bogotá.

Salazar, D., R. Alvar, R. González, D. Hernández, H. Ramírez, F. Vega y S. Yrarrázaval 2017. Ciencia y política en la arqueología chilena: el caso de Fondecyt. Revista Chilena de Antropología 35:186-217.

Salerno, V. 2013. Arqueología pública: reflexiones sobre la construcción de un objeto de estudio. Revista Chilena de Antropología 27 (1):7-37.

Sanoja, M. e I. Vargas 1993. Perspectivas de la antropología en Venezuela: el caso particular de la arqueología. En Balance de la Antropología en América Latina y el Caribe, editado por L. Arizpe y C. Serrano, pp. 75-104. Universidad Autónoma de México, México DF.

Seguel, R. 1997. Educación patrimonial: una estrategia para la preservación de sitios arqueológicos en la Comuna de Los Vilos, Provincia del Choapa. Conserva 1:13-30.

Stone, P. y R. MacKenzie (eds.) 1990. The Excluded Past: Archaeology in Education. Routledge, London.

Stone, P. y B. Molyneaux (eds.) 1994. The Presented Past. Heritage, Museums and Education. Routledge, Londres.

Tully, G. 2007. Community archaeology: general methods and standards of practice. Public Archaeology 6 (3):155-187.

Uribe, M. y L. Adán 2003. Arqueología, poblaciones originarias y patrimonio cultural en el Desierto de Atacama. Chungara Revista de Antropología Chilena 35 (2):295-304

Uribe, M., F. Urrutia y F. Kalazich 2017. Pukara y chullpas de Nama (Tarapacá): Diálogos arqueológicos, patrimoniales y políticos con una comunidad aymara del norte de Chile. Revista Chilena de Antropología 36:362-384.

Valdés, C., M. Massone, R. Sánchez, C. Aldunate, F. Falabella y F. Mena 1994. Arqueología y educación: explorando nuevos horizontes Boletín de la Sociedad Chilena de Arqueología 19:19-22.

Vargas, I. 2006. La Arqueología Social: un paradigma alternativo al angloamericano. Revista de História da Arte e Arqueologia 8:73-78.

Vargas, I. y M. Sanoja 1990. Educación y el manejo político de la historia en Venezuela. Boletín de Antropología Americana 21:89-101.

Vasen, F. 2011. Los sentidos de la relevancia en la política científica. Revista de Ciencia, Tecnología y Sociedad 19 (7):11-46.

Vergara D. 2008. La identidad como objetivo transversal de los procesos cognitivos: aportes de la arqueología y de la elaboración de textos escolares en Chile. En Arqueología y Educación. Perspectivas Contemporáneas, compilado por V. Pernicone y A.M. Rocchietti, pp. 160-180. Tercero en Discordia, Buenos Aires.

Vessuri, H. 2013. ¿Quién es el científico social en el siglo XXI? Comentarios desde los contextos académicos y aplicados y desde la corriente principal y la periferia. Sociológica 28 (79):201-231.

Vessuri, H., J.C. Guédon y A.M. Cetto 2014. Excellence or quality? Impact of the current competition regime on science 
and scientific publishing in Latin America and its implications for development. Current Sociology 62 (5):647-665.

Vilches, F., P. Ayala, C. Garrido y U. Cárdenas 2015. The contemporary past of San Pedro de Atacama, Northern Chile: Public archaeology? Archaeologies 11 (3):372-399.
Young, M. 1995. Desarrollo Integral del Niño en la Primera Infancia; Desafíos y Oportunidades. Banco Mundial. OPS.

Young, D. y P. Tamir 1977. Finding out what students know. The Science Teacher 44:27-28.

\section{Notas}

${ }^{1}$ Un ejemplo de cuaderno de estudiante puede descargarse directamente en el siguiente enlace: https://mail.google.com/ mail/u/2/\#inbox/FMfcgxwDqTfZLPZDGjTgvFrDSGkztGSC

${ }^{2}$ Margen de Error: 8\%, Nivel de Confianza: 95\%

${ }^{3}$ Lo anterior no significa en caso alguno suscribir a una visión relativista del conocimiento académico. Creemos que las posibilidades de la academia y la ciencia en general de justificar sus saberes apelando a la experiencia empírica es lo que le entrega también su legitimidad para generar aportes en el campo político o educativo. Pero la justificación de los saberes académicos no es absoluta ni inamovible, y requiere procesos de permanente revisión y crítica. 